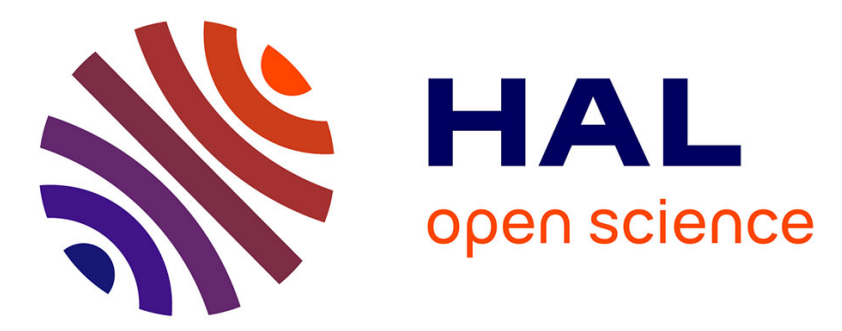

\title{
Structure of single sheet iron oxides produced from surfactant interlayered green rusts
}

Zhou Yin, Knud Dideriksen, Mustapha Abdelmoula, Christian Ruby, Frederick Marc Michel, Morten Jannik Bjerrum, Christian Hansen

\section{- To cite this version:}

Zhou Yin, Knud Dideriksen, Mustapha Abdelmoula, Christian Ruby, Frederick Marc Michel, et al.. Structure of single sheet iron oxides produced from surfactant interlayered green rusts. Applied Clay Science, 2019, 170, pp.86-96. 10.1016/j.clay.2019.01.009 . hal-02000218

\section{HAL Id: hal-02000218 https://hal.science/hal-02000218}

Submitted on 6 Oct 2021

HAL is a multi-disciplinary open access archive for the deposit and dissemination of scientific research documents, whether they are published or not. The documents may come from teaching and research institutions in France or abroad, or from public or private research centers.
L'archive ouverte pluridisciplinaire HAL, est destinée au dépôt et à la diffusion de documents scientifiques de niveau recherche, publiés ou non, émanant des établissements d'enseignement et de recherche français ou étrangers, des laboratoires publics ou privés. 


\title{
Structure of Single Sheet Iron Oxides Produced from 2
}

Surfactant interlayered Green Rusts

\author{
Zhou Yin ${ }^{* 1}$, Knud Dideriksen ${ }^{2}$, Mustapha Abdelmoula ${ }^{3}$, Christian Ruby ${ }^{3}$, F. Marc Michel ${ }^{4}$, Morten \\ Jannik Bjerrum $^{2}$, Hans Christian B. Hansen ${ }^{1}$ \\ ${ }^{1}$ Dept. of Plant and Environmental Sciences, University of Copenhagen, Denmark \\ ${ }^{2}$ Dept. of Chemistry, University of Copenhagen, Denmark \\ ${ }^{3}$ Laboratoire de Chimie Physique et Microbiologie pour l'Environnement - LCPME UMR 7564 CNRS-Université de \\ Lorraine, France. \\ ${ }^{4}$ Dept. of Geosciences, Virginia Tech, Blacksburg, Virginia 24061-0420, United States
}

\section{GRAPHIC ABSTRACT}

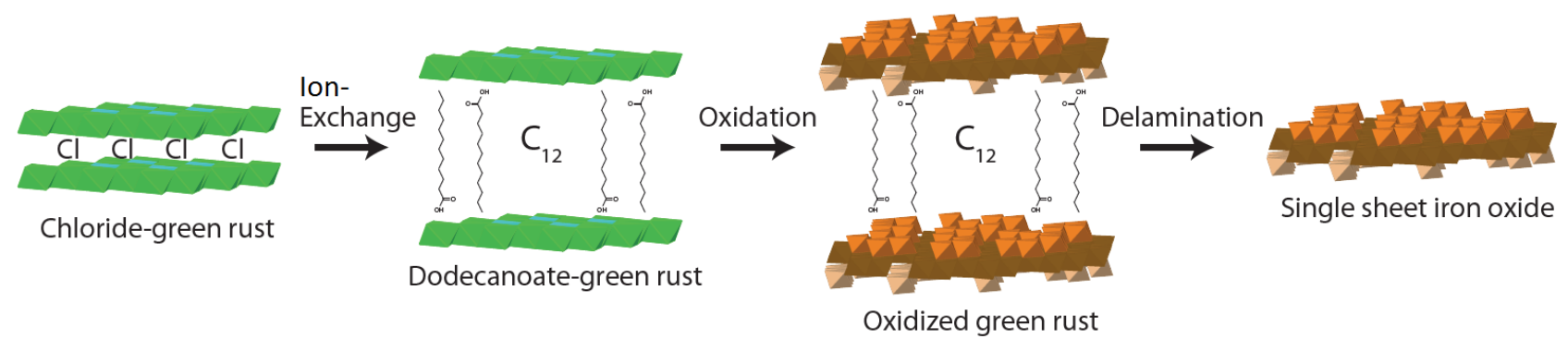

ABSTRACT

Two-dimensional (2D) single sheets formed via delamination of Layered Double Hydroxides (LDHs) are of great interest because of their high reactive surface area and unique chemical and physical properties. Here, we focus on formation and properties of single sheet iron oxides (SSI) that may be used as sorbents, electro- and photocatalysts. We have developed a method for synthesis of SSIs from the $\mathrm{Fe}^{\mathrm{II}}-\mathrm{Fe}^{\mathrm{III}} \mathrm{LDH}$ (green rust, GR) using surfactant intercalation of preformed GR, followed by aerial oxidation and delamination. The average height of the SSIs from AFM is $1 \mathrm{~nm}$ and the lateral dimensions vary from 20 to $100 \mathrm{~nm}$. Selected area electron diffraction of SSI shows a hexagonal pattern with $\mathrm{d} \approx 0.28 \mathrm{~nm}$ consistent with diffraction along [001] in metal hydroxide layers in GR. Chemical analysis, thermogravimetric analysis and X-ray photoelectron spectra analysis lead to SSI formula of $\mathrm{FeO}_{0.82}(\mathrm{OH})_{1.38} \cdot 0.7 \mathrm{H}_{2} \mathrm{O}$. For the oxidized, surfactantintercalated GR and SSI, pair distribution functions from high energy X-ray scattering data demonstrate that two distinct interatomic distances exist for first neighbor Fe-Fe pairs, somewhat similar to the patterns for ferrihydrite and goethite, but in contrast to the single $\mathrm{Fe}-\mathrm{Fe}$ distance 
observed for the unoxidized GR. A modeled structural rearrangement with vertical displacements of Fe atoms from the original hydroxide layer to form a trilayer with Fe polyhedra that are linked via both corner- and edge-sharing produced a PDF in agreement with the main features of the measured pattern. Mössbauer spectroscopy shows that the SSI orders magnetically at $130 \mathrm{~K}$ and that the hyperfine parameters are distinct for SSI and different from other iron oxides such as ferrihydrite and feroxyhite. The synthesis pathway via $\mathrm{GR}_{\mathrm{C} 12}$ is critical for formation of SSI as the "insolating" $\mathrm{C} 12$ interlayer hinders bonding and polymerization between $\mathrm{Fe}^{\mathrm{III}}-\mathrm{O} / \mathrm{OH}$ octahedra across interlayers during oxidation and thus only structural reorganisations of single brucitic $\mathrm{Fe}^{\mathrm{II}}-\mathrm{Fe}^{\mathrm{III}}$ hydroxide layers can take place during oxidation with no possibilities for nucleation of iron oxides with higher crystallinity like goethite. The strong increase of single- and double coordinated $\mathrm{O} / \mathrm{OH}$ groups in the SSI compared with the parent GRs predicts a high reactivity of SSI as surface complexation sorbents.

KEYWORDS: Green Rust, Delamination, Two-dimensional iron oxide, Pair distribution function

\section{INTRODUCTION}

Layered Double Hydroxides (LDHs) consist of positively charged, brucite-type metal hydroxide layers separated by interlayers of charge compensating anions and water molecules. ${ }^{1}$ Belonging to the hydrotalcite group, they can be represented by the general formula $\left[\mathrm{M}_{\mathrm{a}}{ }_{1-\mathrm{x}}^{\mathrm{II}} \mathrm{M}_{\mathrm{b}}{ }_{\mathrm{x}}^{\mathrm{III}}(\mathrm{OH})_{2}\right]^{\mathrm{x}+}\left[\mathrm{A}^{\mathrm{n}-}\right.$ $\mathrm{x} / \mathrm{n}]^{\mathrm{x}-} \cdot \mathrm{mH}_{2} \mathrm{O}$, where $\mathrm{M}_{\mathrm{a}}{ }^{\mathrm{II}}$ and $\mathrm{M}_{\mathrm{b}}{ }^{\mathrm{III}}$ represent di- and trivalent metal cations in the metal hydroxide layer ( $\mathrm{x}$ is in the range from 0.2 to 0.33 ), and $\mathrm{A}^{\mathrm{n}-}$ is an $\mathrm{n}$-valent anion in the interlayer. ${ }^{2}$ Recently, the successful preparation of two-dimensional (2D) single sheets of a thickness of $1 \mathrm{~nm}$ via delamination of LDHs have been described. ${ }^{3,4}$ These nanosheets, which are made of single or a few stacked layers derived from the parent LDH, exhibit specific chemical and physical properties, including superior electron mobility and high catalytic activity. Due to their heritage from LDHs, the chemical composition and properties of the parent LDHs are thought to be crucial for the chemical and physical properties of the delaminated material.

The synthesis of these nanosheets can be generally classified into two approaches: "bottom-up" and "top-down". The "bottom-up" method involves direct synthesis of the nanosheet materials from solution by creating a physical/chemical micro-environment for oriented growth of single-layered LDH nanosheets. ${ }^{5}$ The "top-down" approach is the more widely developed method, which is based 
on delamination of the LDHs. However, since the charge density of LDHs is significantly higher than that of most other lamellar solids, it has been difficult to achieve full delamination. ${ }^{6}$ Key factors that control the success of delamination are the electrostatic attraction on the metal hydroxide layers of the LDHs and property of the solvent used for delamination. To weaken the electrostatic attraction between the layers, several attempts have been taken to enlarge the interlayer distance by exchanging inorganic interlayer anions with larger organic anionic molecules. By intercalation of surfactants, amino acids or other long-chain carboxylates, the electrostatic attraction between the positively charged metal hydroxide layers and the anionic interlayers is weakened, and subsequent delamination of LDHs is facilitated. After ion exchange, delamination in formamide, butanol, water and other reagents have been reported as a result of osmotic swelling of LDHs caused by the interaction between the interlayer anions and the solvents. ${ }^{4,7,8}$

Structural investigations of exfoliated LDH products demonstrate that the local coordination around the divalent and trivalent metal atoms remains unchanged after delamination. For example, Leroux et al. $^{9}$ demonstrated by use of X-ray absorption fine structure (EXAFS) that the local ordering around $\mathrm{Zn}$ atoms in $\mathrm{Zn}-\mathrm{Al} \mathrm{LDHs}$ was unaffected by delamination. More recently, Funnell et al. $^{10}$ reported the atomic-scale structure of a $\mathrm{Zn}-\mathrm{Al} \mathrm{LDHs}$ by reverse Monte Carlo (RMC) modeling of pair distribution function (PDF) analysis. The refined data showed that after delamination, the coordination of $\mathrm{Zn}$ and $\mathrm{Al}$ atoms were similar to that found in the metal hydroxide layers of $\mathrm{Zn}-\mathrm{Al} \mathrm{LDHs}$, whereas there was no evidence of strong $\mathrm{Zn}-\mathrm{Al}$ ordering within the delaminated material. ${ }^{11}$

The focus in this work is on the delaminated products formed from so-called green rusts. Green rusts (GRs) are $\mathrm{Fe}^{\mathrm{II}}-\mathrm{Fe}^{\mathrm{III}} \mathrm{LDH}$ compounds with the chemical formula $\left[\mathrm{Fe}^{\mathrm{II}}(1-\mathrm{x}) \mathrm{Fe}^{\mathrm{III}}{ }_{\mathrm{x}}(\mathrm{OH})_{2}\right]^{\mathrm{x}+} \cdot[(\mathrm{x} / \mathrm{n})$ $\left.\mathrm{A}^{\mathrm{n}-}, \mathrm{y} \mathrm{H}_{2} \mathrm{O}\right]^{\mathrm{x}-}$. In our previous work, we have used the "top-down" approach to produce $2 \mathrm{D}$ single sheets of $\mathrm{Fe}^{\mathrm{III}}$ hydroxides (SSI) from directly synthesized dodecanoate intercalated GRs. ${ }^{12,13}$ In this approach, the dodecanoate intercalated GR is oxidized by $\mathrm{O}_{2}$ to its corresponding $\mathrm{Fe}^{\mathrm{III}}$ form before delamination via dispersion in alkaline solutions. ${ }^{18}$ Compared to other Fe ${ }^{\mathrm{III}}$ hydroxide particles, SSI with a thickness of $1 \mathrm{~nm}$ has the highest possible surface area to volume ratio ideally with all Fe$\mathrm{OH}$ groups in the structure exposed to the solution. Because of their high specific surface area, SSIs have interesting uses as sorbents (e.g. for phosphate) ${ }^{13}$ and for electro-catalysts. ${ }^{14,15}$ A first structural study has shown that SSI has a thickness of $1 \mathrm{~nm}$ and lateral sizes ranging from 100 to $200 \mathrm{~nm}^{12}$. The authors claimed that the trioctahedral structure of the parent $\mathrm{Fe}^{\mathrm{II}}-\mathrm{Fe}^{\mathrm{III}}$ hydroxide 
layers were kept intact during oxidation and thus inherited by the delaminated material. However, whether this is true is still questionable. In GR, the Fe atoms are octahedrally coordinated to O atoms and the octahedra are linked via edge-sharing to form planar layers. In such a structure, all nearest neighbor $\mathrm{Fe}-\mathrm{Fe}$ distances are almost the same. ${ }^{16}$ However, if the local atomic structure changes during delamination, other types of $\mathrm{Fe}^{\mathrm{III}}$ hydroxides such as feroxyhite, ferrihydrite, lepidocrocite and goethite might form. In fact, these $\mathrm{Fe}^{\mathrm{III}}$ hydroxides are readily formed by oxidation of GRs, ${ }^{17,18}$. However, these compounds have Fe ${ }^{\mathrm{III}}$ octahedra linked by both corner and edge-sharing and consequently features several distances for nearest neighbor $\mathrm{Fe}-\mathrm{Fe}$ pairs. ${ }^{19-21}$ Therefore, determination of Fe-Fe distances in the SSI could reveal if brucite-like layers in the GR is kept intact during delamination, or reorganization has taken place. In the present investigation, we have been using a variety of techniques including X-ray diffraction, infrared spectroscopy, Mössbauer spectroscopy, X-ray photoelectron spectra (XPS), and high-energy X-ray scattering to obtain further insight on the structure of the SSI phase. Pair distribution function (PDF) analysis of X-ray scattering data is a powerful technique to gain structural information for phases lacking longrange order. The PDF methods have been applied previously to bulk $\mathrm{GR}^{22}$ and have given a useful insight on metal coordination.

In this study, we have developed a robust method to synthesize SSI via a dodecanoate intercalated GR $\left(\mathrm{GR}_{\mathrm{C} 12}\right)$ formed by ion exchange of chloride-GR. Subsequently, the $\mathrm{GR}_{\mathrm{C} 12}$ has been oxidized by air followed by alkaline delamination to produce SSI. The main objective of this work has been to investigate the structure of the resulting SSI and in particular to test if the brucite-like $\mathrm{Fe}^{\mathrm{II}}-\mathrm{Fe}^{\mathrm{III}}$ hydroxide layers in GR are kept intact during oxidation and subsequent delamination. The results have important implications for the use of SSI as sorbents and catalyst materials.

\section{EXPERIMENTAL SECTION}

\subsection{Materials}

All chemicals were of analytical grade and used without further purification. Glycine $\left(\mathrm{NH}_{2} \mathrm{CH}_{2} \mathrm{COOH}, 99 \%\right)$, dodecanoic acid $\left(\mathrm{C}_{12} \mathrm{H}_{24} \mathrm{O}_{2}, 99 \%\right)$, iron chloride $\left(\mathrm{FeCl}_{3}, 99 \%\right)$, sodium chloride $(\mathrm{NaCl}, 99 \%)$ and sodium hydroxide $(\mathrm{NaOH}, 98 \%)$, iron nitrate nonahydrate $\left(\mathrm{Fe}\left(\mathrm{NO}_{3}\right)_{3} \cdot 9 \mathrm{H}_{2} \mathrm{O}, 99 \%\right)$ were all obtained from Sigma-Aldrich. A $0.5 \mathrm{M} \mathrm{FeCl}_{2}$ stock solution was prepared according to the method described by Koch and Hansen ${ }^{23}$. Thus, $3.5 \mathrm{~g} \mathrm{Fe}^{0}$ powder $(10 \mu \mathrm{m}$, EMSURE, 99\%) was mixed with $100 \mathrm{ml}$ of $1 \mathrm{M} \mathrm{HCl}\left(\mathrm{O}_{2}\right.$ free $)$ in a glass beaker and magnetically 
stirred in a $70{ }^{\circ} \mathrm{C}$ water bath until no further $\mathrm{H}_{2}$ was formed. Milli-Q water (18.2 M $\Omega$ ) and ultrapure argon (purity $>99.99 \%$ ) were used throughout the experimental work. A pH-stat (Metrohm, 719 Titrino) was employed for all synthesis to maintain $\mathrm{pH}$ at 8.0 via $1 \mathrm{M} \mathrm{NaOH}$ injection. All synthesis was conducted in an anoxic chamber $\left(95 \% \mathrm{~N}_{2}\right.$ and $5 \% \mathrm{H}_{2}$, Coy Laboratories, Michigan, USA).

\subsection{Synthesis}

Single sheet iron oxides (SSI) were synthesized by anion exchanging chloride intercalated GR $\left(\mathrm{GR}_{\mathrm{Cl}}\right)$ with dodecanoate, followed by solid state oxidation and delamination in $0.1 \mathrm{M} \mathrm{NaOH}$. Synthesis of $\mathrm{GR}_{\mathrm{Cl}}$ followed the method described by $\mathrm{Yin}^{24}$ comprising co-precipitation of $\mathrm{Fe}^{2+}$ and $\mathrm{Fe}^{3+}$ in the presence of glycine at a constant $\mathrm{pH}$ of $8.0( \pm 0.1)$. First, $400 \mathrm{ml}$ of $70 \mathrm{mM}$ glycine and $245 \mathrm{mM}$ of $\mathrm{NaCl}$ solutions were added to a synthesis glass flask followed by capping the flask with a rubber septum and providing in- and outlets for flushing Ar gas $\left(30 \mathrm{ml} \mathrm{min}^{-1}\right)$ to avoid oxidation by air. The synthesis suspension was stirred using a magnetic bar (300 rpm). After adjustment of $\mathrm{pH}$ of the solution to 8.0 by dosing $1 \mathrm{M} \mathrm{NaOH}, 20 \mathrm{ml} 0.5 \mathrm{M} \mathrm{FeCl}_{2}$ stock solution was injected into the synthesis flask and $\mathrm{pH}$ re-adjusted to 8.0 using the $\mathrm{pH}$-stat followed by injection of $15 \mathrm{ml} 0.1 \mathrm{M}$ $\mathrm{FeCl}_{3}$ to the synthesis flask at a rate of $10 \mathrm{ml} \mathrm{min}^{-1}$ while $\mathrm{pH}$ was controlled at 8.0 using the $\mathrm{pH}-$ stat. After synthesis, the precipitated $\mathrm{GR}_{\mathrm{Cl}}$ was transferred to the anoxic chamber and separated by centrifugation at $4000 \mathrm{~g}$ for $5 \mathrm{~min}$.

The $\mathrm{GR}_{\mathrm{Cl}}$ product was transferred to a glass flask containing $200 \mathrm{ml}$ Ar-bubbled $0.1 \mathrm{M}$ dodecanoate dissolved in $40 \%$ ethanol ( $\mathrm{pH}$ adjusted to 8 using $1 \mathrm{M} \mathrm{NaOH}$ ). The solution was stirred $\left(300 \mathrm{rpm}\right.$ ) for three hours to exchange chloride with dodecanoate. The resulting $\mathrm{GR}_{\mathrm{C} 12}$ was further washed with Ar-bubbled ethanol and water. Then, the $\mathrm{GR}_{\mathrm{C} 12}$ was separated by centrifugation at $8000 \mathrm{~g}$ for $5 \mathrm{~min}$, frozen as a suspension at $-80^{\circ} \mathrm{C}$ overnight and transferred to a freeze-dryer (Christ Loc-I) at $-40{ }^{\circ} \mathrm{C}$. Finally, the dry $\mathrm{GR}_{\mathrm{C} 12}$ was ground by mortar and pestle and oxidized by $\mathrm{O}_{2}$ by exposing a thin layer $(1 \mathrm{~mm})$ of the powder to air for two days. The color changed gradually from green via brown to final brownish-orange.

The so obtained oxidized $\mathrm{GR}_{\mathrm{C} 12}(1 \mathrm{~g})$ was mixed with $1 \mathrm{~L}$ of $0.1 \mathrm{M} \mathrm{NaOH}$ in a polyethylene beaker and stirred $(300 \mathrm{rpm})$ for $24 \mathrm{~h}$ to achieve delamination. Then the suspension was rinsed to remove dodecanoate by centrifugation at $8000 \mathrm{~g}$ for $5 \mathrm{~min}$ and re-dispersion of the precipitate in ethanol. This washing and centrifugation procedure was repeated three times followed by a final washing with water, centrifugation and re-dispersion in $20 \mathrm{ml}$ Milli-Q water. Part of the suspension 
was frozen and freeze-dried to obtain powders for later characterization. Approximately $0.63 \mathrm{~g}$ SSI was obtained from $1 \mathrm{~g}$ of oxidized $\mathrm{GR}_{\mathrm{C} 12}$.

For reference, feroxyhite was synthesized by the method of Pollard. ${ }^{25}$ Two-line ferrihydrite and goethite were synthesized using the methods given in Cornell and Schwertmann. ${ }^{16}$

\subsection{Characterization}

Powder X-ray diffraction (XRD) data were collected using a Siemens D5000 X-ray diffractometer using monochromated Co-K $\alpha$ radiation (wavelength $\lambda=1.79 \AA$ ) and a scanning rate of $0.6^{\circ} 2 \theta \mathrm{min}^{-1}$ in the $2 \theta$ range $1.5-80^{\circ}$. Suspensions of washed and centrifuged GR materials were added as concentrated droplets onto glass plates, dried in the anoxic chamber for $12 \mathrm{~h}$, and subsequently wetted with glycerol to avoid oxidation. For oxidized $\mathrm{GR}_{\mathrm{C} 12}$ and for SSI the dried materials were scanned as unoriented dry packed powders.

Crystallite sizes D were estimated from basal reflections (c-axis) by use of the Scherrer equation: $^{26}$

$$
\mathrm{D}=0.9 \lambda /(\beta \cos \theta)
$$

where $\lambda$ is the wavelength of the $\mathrm{X}$-rays, $\theta$ is the diffraction angle of the basal reflection, and $\beta$ is the peak broadening at the half-maximum intensity.

The $\mathrm{Fe}^{\mathrm{II}}$ and $\mathrm{Fe}^{\mathrm{III}}$ contents in GRs were quantified by a modified phenanthroline method. ${ }^{24}$ For determination of the $\mathrm{Fe}^{\mathrm{III}}$ content in the SSI, $50 \mathrm{mg}$ of dry SSI was dissolved completely in $50 \mathrm{ml} 6$ $\mathrm{M} \mathrm{HCl}$ at $80{ }^{\circ} \mathrm{C}$, followed by iron determination by atomic absorption spectroscopy. Thermogravimetric analysis (TGA) was performed using a Pyris 1 DSC, with a heating rate of 20 ${ }^{\circ} \mathrm{C} \min ^{-1}$ over a temperature range of 24 to $700{ }^{\circ} \mathrm{C}$. Twenty $\mathrm{mg}$ of the sample was analyzed in a nitrogen atmosphere.

Fourier-transform infrared (FTIR) spectra were recorded by scanning tablets (diameter $13 \mathrm{~mm}$ ) of samples $(0.5 \mathrm{mg}$ ) mixed with dry $\mathrm{KBr}$ (IR spectroscopy grade, Sigma-Aldrich, $300 \mathrm{mg}$ ) using a Fourier transform infrared spectrometer (Perkin-Elmer Frontier TM ) in the range of 400 to 4000 $\mathrm{cm}^{-1}\left(4 \mathrm{~cm}^{-1}\right.$ resolution, 3 scans $)$.

Atomic force microscopy (AFM) images were acquired in tapping mode using a Si tip cantilever (Olympus AC240) on a mica surface with a force constant of $5 \mathrm{~N} \mathrm{~m}^{-1}$. Samples were prepared by 
running droplets of diluted SSI-suspensions over the mica surface and taking the AFM measurements immediately after blow-drying with nitrogen. Transmission electron microscopy (TEM) images were obtained with a Phillips CM-20 with an accelerating voltage of $200 \mathrm{kV}$. The SSI powder was first redispersed in ethanol, and droplets of the suspension were dried on a microscope copper grid.

Elemental analysis and XPS were performed using a Kratos Axis Ultra X-ray photoelectron spectrometer equipped with a monochromated $\mathrm{Al} \alpha \mathrm{X}$-ray $(\mathrm{h} v=1486.6 \mathrm{eV})$ operated at $120 \mathrm{~W}$. The base pressure in the analytical chamber was about $10^{-9}$ mbar. Spectra were collected at normal takeoff angle $\left(90^{\circ}\right)$, and the analysis area was $700 \times 300 \mu \mathrm{m}^{2}$. Wide scans were recorded using an analyzer pass energy of $160 \mathrm{eV}$ and narrow scans using a pass energy of $20 \mathrm{eV}$. Survey (broad scan) spectra were collected at $160 \mathrm{eV}$ pass energy and all high-resolution scans (i.e. C1s) were done at $20 \mathrm{eV}$ pass energy. The instrument geometry allows about $0.75 \mathrm{eV}$ energy resolution at $20 \mathrm{eV}$ pass energy. Charge compensation was adjusted for each sample to obtain the narrowest linewidths. All binding energies are referenced to adventitious $\mathrm{C}(284.6 \mathrm{eV})$. The XPS spectra were fitted using the $\mathrm{X}$-version 2.2.11 software.

Mössbauer spectroscopy was performed at $297 \mathrm{~K}, 130 \mathrm{~K}, 77 \mathrm{~K}, 35 \mathrm{~K}$, and $9 \mathrm{~K}$ with a constant acceleration Mössbauer spectrometer and 512 multichannel analyzer (Halder Electronic Gmbh), and a $50 \mathrm{mCi}$ source of ${ }^{57} \mathrm{Co}$ in $\mathrm{Rh}$ maintained at RT. Data were obtained from appropriate amounts (10 $\mathrm{mg}$ of $\mathrm{Fe}$ per $\mathrm{cm}^{2}$ ) of solid samples to get optimal experimental conditions. In order to avoid the condensation of oxygen and water on the walls of the cryostat, samples were quickly transferred under inert He atmosphere to a cold-head cryostat manufactured by Advanced Research Systems, equipped with vibration isolation stand and developed in the LCPME Laboratory. Mössbauer spectra were collected in transmission mode. The $50 \mathrm{mCi}$ source of ${ }^{57} \mathrm{Co}$ in $\mathrm{Rh}$ matrix was maintained at room temperature and mounted at end of a Mössbauer velocity transducer. The spectrometer was calibrated with a $25 \mu \mathrm{m}$ foil of $\alpha$-Fe at RT. Analysis of the Mössbauer spectra consisted of least-square fitting of data with a combination of two-peak quadrupole components (doublets) and, when present, six-peak magnetic hyperfine components (sextets). The Lorentzianshape lines model from Recoil software (Ottawa University) could not be used to fit experimental data that give rise to the broadened spectra induced by the structural disorder. Therefore, another model based on the Voigt-based fitting method of Rancourt and Ping ${ }^{27}$ for quadrupole splitting distribution (QSDs) and magnetic hyperfine fields (HFDs), was used to fit spectra. 
For high energy X-ray scattering, all samples were loaded in glass capillary tubes and sealed with paraffin. For oxidation-sensitive GR samples, sample loading was performed inside the anaerobic chamber and transferred out of the chamber 4 days before measurement. Previous tests of the sample preparation showed that even rapidly oxidizing samples remain intact in the tubes for at least a week. ${ }^{28}$ High energy X-ray scattering measurements were performed at beamline 11 ID-B at the Advanced Photon Source, Argonne National Laboratory, using an X-ray energy of $58.66 \mathrm{keV}(\lambda$ $=0.2113 \AA$ ). The samples were placed approximately $15 \mathrm{~cm}$ from a $40 \mathrm{~cm}$ by $40 \mathrm{~cm}$, amorphous $\mathrm{Si}$ $2 \mathrm{D}$ detector. The geometry of the setup was calibrated from the measurement of a $\mathrm{CeO}_{2}$ standard using the software Fit2D. ${ }^{29,30}$ Fit2D was also used to convert the 2D data into polarization corrected 1D data, from which PDFs was obtained with the software PDFGETX2. ${ }^{31,32}$ Data treatment with PDFGETX2 included subtraction of the background measured for an empty glass capillary tube, subtraction of incoherent scattering, normalization by the average atomic scattering cross-section of the sample, and a correction for non-linear detector efficiency. ${ }^{33}$ In the treatment, the composition of the material was assumed to be: $\mathrm{GR}_{\mathrm{Cl}}$ : $\mathrm{Fe}_{4} \mathrm{O}_{12} \mathrm{H}_{16} \mathrm{Cl}$; $\mathrm{GR}_{\mathrm{C} 12}$ and oxidized $\mathrm{GR}_{\mathrm{C} 12}$ : $\mathrm{Fe}(\mathrm{OH})_{3} \mathrm{C}_{4}$; $\mathrm{SSI}$; feroxyhite, ferrihydrite: $\mathrm{Fe}(\mathrm{OH})_{3}$; and goethite: $\mathrm{FeOOH}$. Fourier transform of the $\mathrm{Q}\left[\mathrm{S}(\mathrm{Q})^{-1}\right]$ was performed using a maximum $Q$ value of $24 \AA^{-1}$ to yield the reduced pair distribution function, $G(r)$.

Modeling of PDFs was performed with the software PDFgui, ${ }^{34}$ which is routinely used to fit crystalline material, and DiffPy-CMI, which allows more versatile modeling of PDFs including those for molecules. ${ }^{35}$ This approach has been applied to simulate the PDFs of a wide variety of nanosystems. ${ }^{36,37}$ In the modeling, an instrumental dampening of 0.047 was refined from the measurement of a well crystalline synthetic goethite using the structure from Hoppe. ${ }^{38}$ During the PDFgui modeling, the parameters were fitted in the order: 1) scaling, 2) size of spherical coherently scattering as well as correlated atomic movement, $\left.\delta_{2}, 3\right)$ unit cell dimensions and 4) atomic isotropic displacement parameters. For the DiffPy-CMI modeling, a minimum Q of $1 \AA^{-1}$ was assumed and the value for correlated atomic movement, $\delta_{2}$, was set to 3 .

\section{RESULTS AND DISCUSSION}

\subsection{Layer Structure of SSI}

The powder X-ray diffraction patterns of $\mathrm{GR}_{\mathrm{Cl}}$ and $\mathrm{GR}_{\mathrm{C} 12}$ demonstrate the formation of wellcrystallized LDH with the hydrotalcite-type structure (Figure 1). ${ }^{39,40}$ The $\mathrm{GR}_{\mathrm{Cl}}$ is characterized by marked basal reflections, resulting in a basal spacing of $\mathrm{GR}_{\mathrm{Cl}}$ of $\left(\mathrm{d}_{001}+2 \times \mathrm{d}_{002}+3 \times \mathrm{d}_{003}\right) / 3=0.79$ 
$238 \mathrm{~nm}$, in agreement with the literature. ${ }^{41,42}$ The additional peak (Figure 1, trace 1 insert) 239 corresponding to a distance of $0.26 \mathrm{~nm}$ of the third intense peak of $\mathrm{GR}_{\mathrm{Cl}}$. No reflections due to 240 impurities of other $\mathrm{Fe}^{\mathrm{III}}$ hydroxides are observed. The chemical analysis of $\mathrm{GR}_{\mathrm{Cl}}$ shows that the $241 \mathrm{Fe}^{\mathrm{II}} / \mathrm{Fe}^{\mathrm{III}}$ ratio in $\mathrm{GR}_{\mathrm{Cl}}$ is $2.99 \pm 0.065$, in agreement with the ideal ratio of 3 . The exchange of 242 chloride with dodecanoate leads to expansion of the basal spacing from $0.79 \mathrm{~nm}$ to $3.5 \mathrm{~nm}$, in line 243 with previous observations of $\mathrm{GRC}_{12},{ }^{13,43}$ demonstrating successful intercalation of dodecanoate. 244 The disappearance of the diffraction peak at $0.79 \mathrm{~nm}$ after ion-exchange in $\mathrm{GR}_{\mathrm{C} 12}$ demonstrates an 245 almost $100 \%$ conversion of $\mathrm{GR}_{\mathrm{Cl}}$ to $\mathrm{GR}_{\mathrm{C} 12}$. By use of the Scherrer equation, the average thickness 246 of the $\mathrm{GR}_{\mathrm{Cl}}$ crystallite in the c-direction is estimated at $17.2 \mathrm{~nm}$ corresponding to $17.2 / 0.79$ or $\sim 22$ 247 layers in the crystallite. For $\mathrm{GR}_{\mathrm{C} 12}$ a similar calculation gives $77.4 / 3.5$ or $\sim 22$ layers, demonstrating 248 that the number of metal hydroxide layers are maintained in the GR during ion-exchange. The $249 \mathrm{GR}_{\mathrm{C} 12}$ shows a series of up to 5 th orders of intense basal reflections, reflecting an equidistant 250 thickness of the layers.

251 After oxidation of the freeze-dried $\mathrm{GR}_{\mathrm{C} 12}$, the $\mathrm{XRD}$ diffraction pattern of ox $\mathrm{GR}_{\mathrm{C} 12}$ is similar to 252 the original $\mathrm{GR}_{\mathrm{C} 12}$, but it shows a slightly lower first-order basal reflection (3.52 nm reduced to 3.34 $253 \mathrm{~nm}$ ), broadening of diffraction peaks. The decreased basal spacing is due to the smaller ionic radii 254 of $\mathrm{Fe}^{\mathrm{III}}$ compared with $\mathrm{Fe}^{\mathrm{II}}$, and higher charge density of the metal hydroxide sheets after oxidation, 255 causing higher electrostatic forces across layers and interlayers. After exposure of the oxidized $256 \mathrm{GR}_{\mathrm{C} 12}$ to sodium hydroxide, the disappearance of basal reflections from the XRD patterns shows 257 that the layered structure has disintegrated and that delamination has taken place. It is hypothesized 258 that delamination takes place due to deprotonation of hydroxyl groups in the $\mathrm{Fe}^{\mathrm{III}}$ hydroxide layers 259 resulting in repulsion and subsequent elimination of interlayer dodecanoate anions. ${ }^{12}$ XRD 260 confirmed that the final products did not contain measurable contents of lepidocrocite, magnetite, 261 hematite, feroxyhite or akaganéite impurities. However, small amounts of impurities of goethite 262 could be observed (Figure 1, trace 4 insert). 


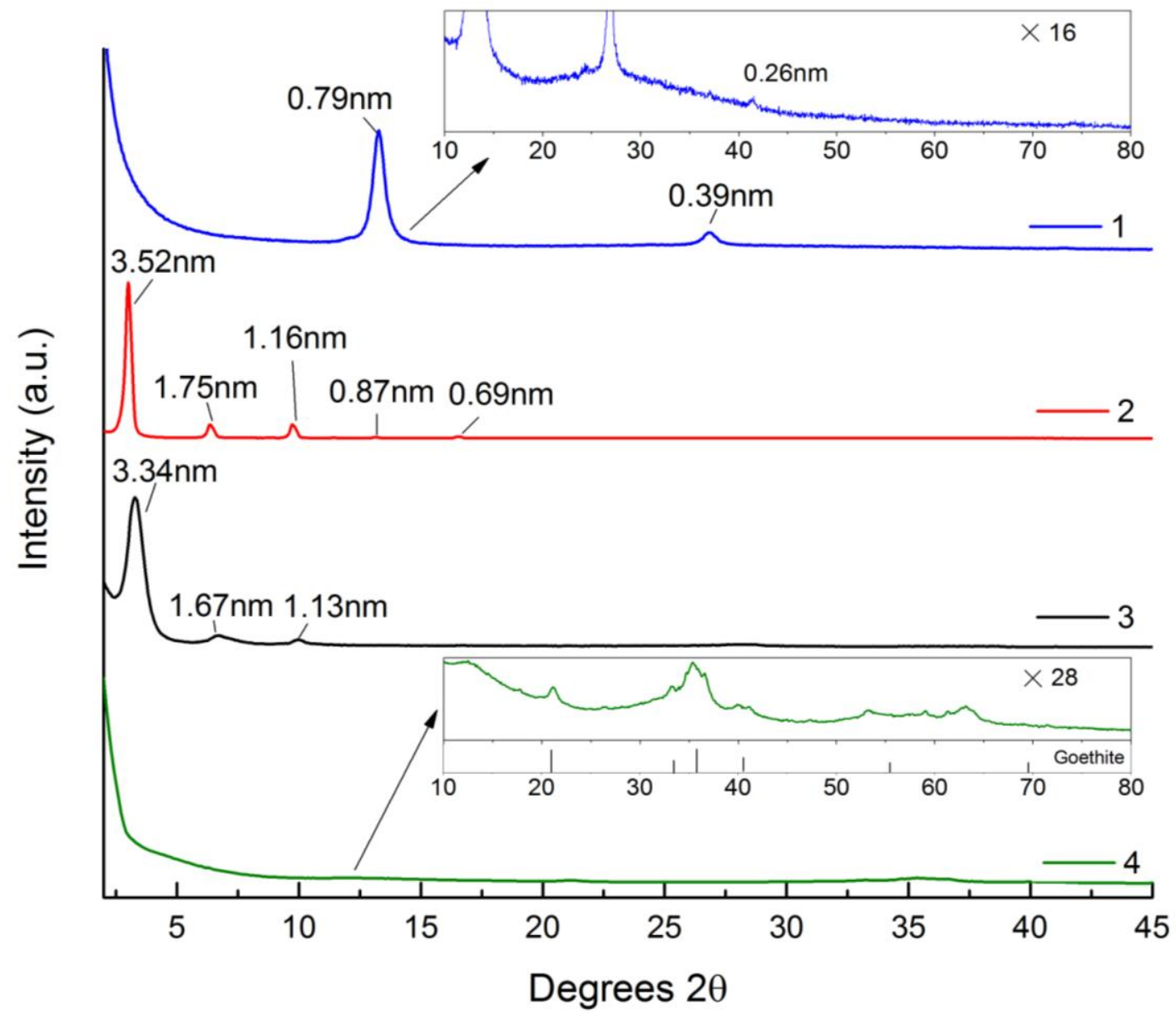

Figure 1. XRD diffractograms of $\mathrm{GR}_{\mathrm{Cl}}$ (profile 1), $\mathrm{GR}_{\mathrm{C} 12}$ (profile 2), oxidized $\mathrm{GR}_{\mathrm{C} 12}$ (profile 3), and SSI (profile 4). The inserts show a detail of XRD diffraction pattern in the range 10 to $80^{\circ}$.

Figure 2 shows the FT-IR spectra for oxidized $\mathrm{GR}_{\mathrm{C} 12}$ and SSI. The FT-IR spectrum of oxidized $\mathrm{GR}_{\mathrm{C} 12}$ shows vibrations from C-H (2975-2850 $\left.\mathrm{cm}^{-1}\right)$ and $\mathrm{COO}^{-}\left(1567-1547 \mathrm{~cm}^{-1}\right)$ that disappear in the SSI, demonstrating that the dodecanoate is effectively removed during delamination. ${ }^{21,22}$ The strong band at $\sim 3425 \mathrm{~cm}^{-1}$ is assigned to the $\mathrm{O}-\mathrm{H}$ stretching vibration of surface $\mathrm{OH}$ groups, which is similar to that of other delaminated LDHs. ${ }^{44,45}$ A broad absorption of SSI in the low-frequency 271 region is assigned to $\mathrm{OH}$ bending bands at $1641 \mathrm{~cm}^{-1}, 1045 \mathrm{~cm}^{-1}$, and $885 \mathrm{~cm}^{-1}$, and Fe-O stretching 272 band at $567 \mathrm{~cm}^{-1}$. None of the two strong O-H stretching vibration $\left(938 \mathrm{~cm}^{-1}, 892 \mathrm{~cm}^{-1}\right)$ for 273 goethite ${ }^{46,47}$ can be observed in the spectra of SSI (Figure S1), demonstrating that the signal of the 274 minor goethite impurity detected by powder XRD in the SSI is below the IR detection limit $(\leq 1 \%)$. 


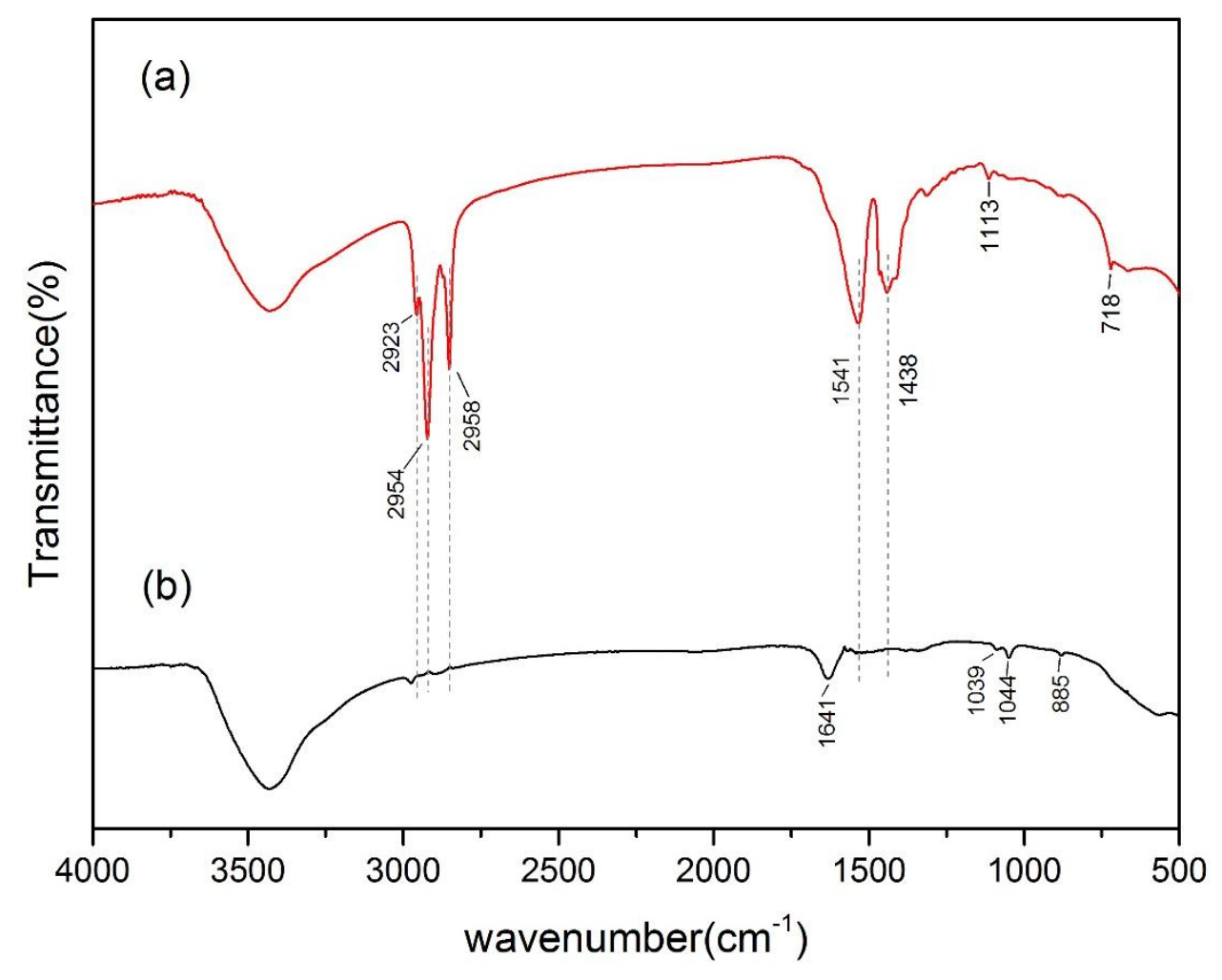

Figure 2. FTIR spectra of (a) oxidized $\mathrm{GR}_{\mathrm{C} 12}$ and (b) SSI

277

\subsection{Morphology}

To visualize the morphology of the SSI, TEM and AFM were used. The AFM images (Figure 3), show two-dimensional platy objects with an average height of about $1 \mathrm{~nm}$, which is more than two times the theoretical thickness of $0.48 \mathrm{~nm}$ for a single $\mathrm{Fe}^{\mathrm{II}}-\mathrm{Fe}^{\mathrm{III}}$ hydroxide layer in $\mathrm{GR}^{48} \mathrm{The}^{\mathrm{SSI}}$ is morphologically irregular, with lateral dimensions from $20 \mathrm{~nm}$ to $100 \mathrm{~nm}$. Thus, they are dimensionally diminished in comparison with the parent GR crystallites, ${ }^{24}$ indicating fracturing of metal hydroxide layers during the synthesis. TEM images of SSI show low-contrast, sheet-like objects with similar lateral dimensions as those seen in AFM (example in Figure 4). The SSI sheets are generally agglomerated but zones exist where the particles are well separated. Selected area electron diffraction (SAED) patterns exhibit hexagonally arranged spots, with the inner spots representing an atomic rows distance $\mathrm{d}$ value of $\sim 0.28 \mathrm{~nm}$. This distance is similar to the distance reported for $\mathrm{GR}_{\mathrm{SO} 4} \cdot{ }^{49-52}$ However, hexagonal patterns also exist for a range of other Fe oxides when observed perpendicular to the hexagonal oxygen packing. ${ }^{51,53}$ 

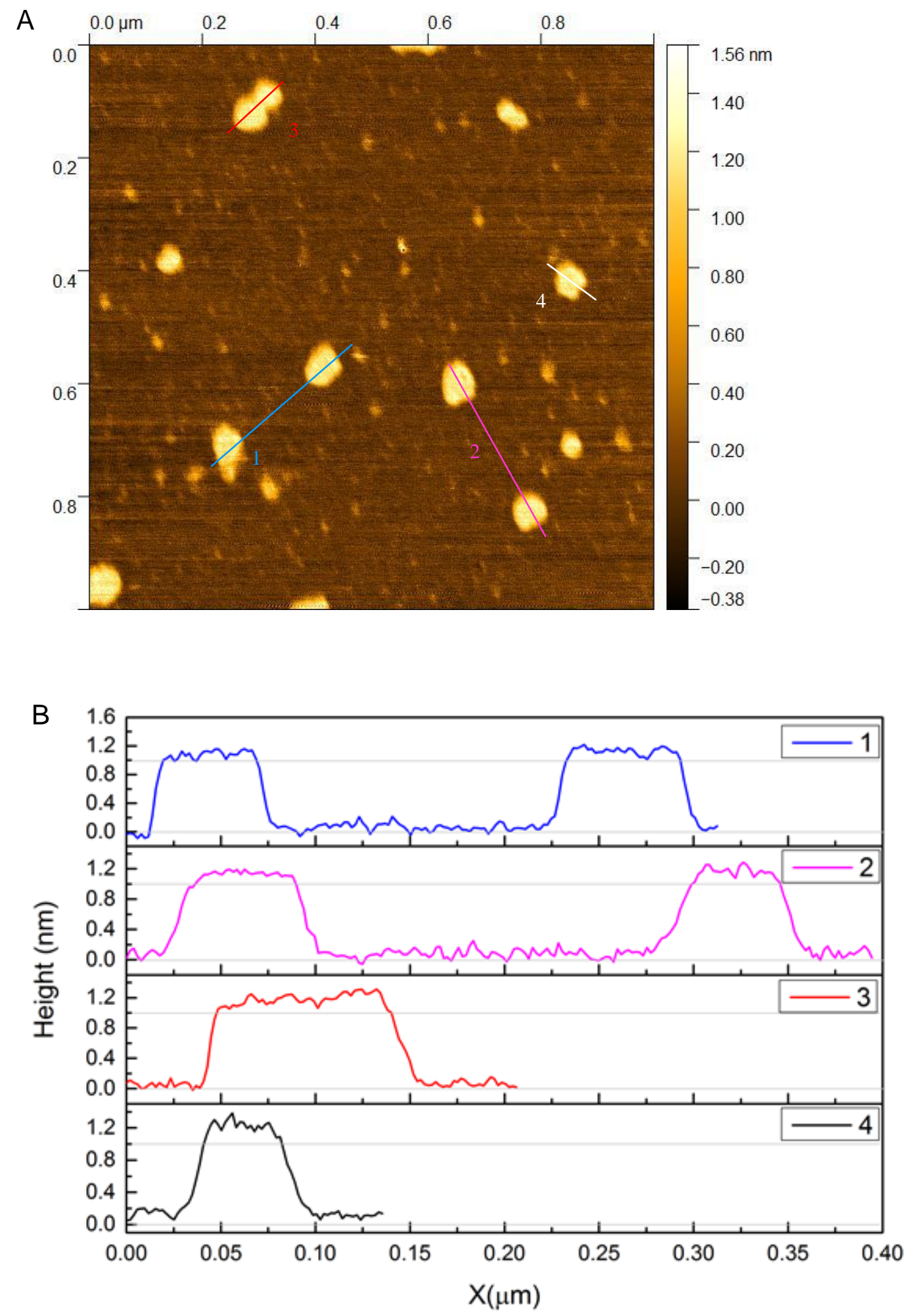

292 Figure 3. (A) Tapping-mode AFM image of SSI deposited on mica. (B) Height profile of the SSI.

293 Profiles 1, 2, 3 and 4 correspond to the trajectories shown in Figure 3 (A). 

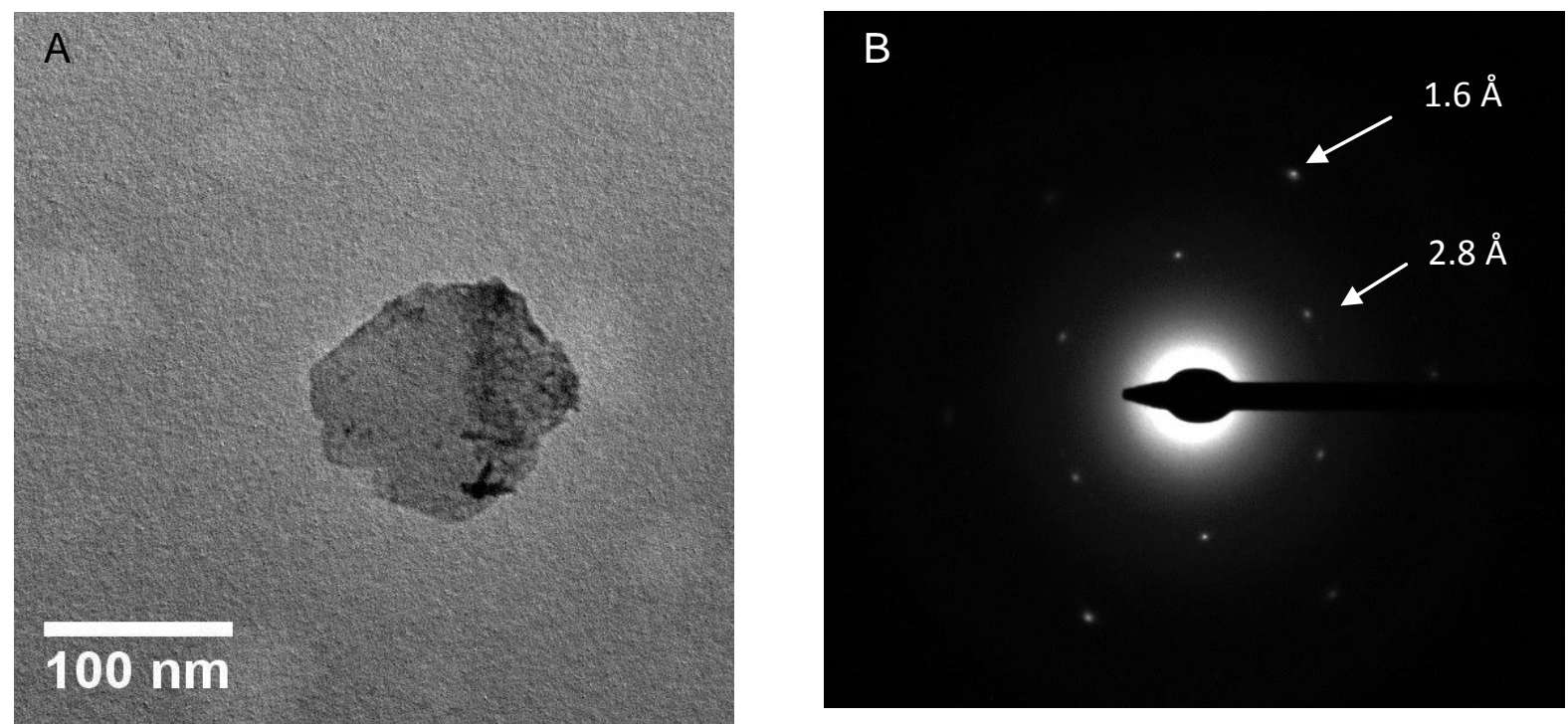

Figure 4. (A) TEM image of SSI nanoparticles. (B) The corresponding selected area electron diffraction (SAED) pattern of SSI. 2.8 $\mathrm{A}$ and $1.6 \AA$ corresponds to the distance between atoms from $\{110\}$ planes or $\{100\}$ planes.

\subsection{Chemical composition of the SSI}

299 The iron content in the SSI is $54 \pm 1 \%(\mathrm{w} / \mathrm{w}, \mathrm{n}=3$ ). TGA of the SSI shows a gradual weight loss 300 from ambient temperature to $300{ }^{\circ} \mathrm{C}$, totaling $20.8 \%$ (Figure S2). The weight of the SSI remains stable at higher temperatures. Attributing the weight loss to water degassing, we reach an approximate composition of $\mathrm{FeO}_{0.82}(\mathrm{OH})_{1.38} \cdot 0.7 \mathrm{H}_{2} \mathrm{O}$ (Equations $\mathrm{S} 1-\mathrm{S} 4$ ). Thus, oxidation of $\mathrm{Fe}^{\mathrm{II}}$ to $\mathrm{Fe}^{\mathrm{III}}$ in the parent GR $\left(\mathrm{Fe}^{\mathrm{II}}{ }_{0.75} \mathrm{Fe}^{\mathrm{III}}{ }_{0.25}(\mathrm{OH})_{2} \mathrm{Cl}_{0.25}\right)$ causes an increase of Fe cationic charge which is compensated by substantial deprotonation. The determined ratio $\mathrm{Fe}: \mathrm{O}$ is 2.88 , close to the theoretical ratio of 3 for $\mathrm{LDH}$ layers.

To independently determine SSI composition and characterize the bonding of oxygen, SSI was examined by XPS. The wide scan spectrum of SSI exhibits peaks at binding energies of 284, 529, 308 718, and $1070 \mathrm{eV}$ which can be ascribed to $\mathrm{C} 1 \mathrm{~s}, \mathrm{O}$ 1s, Fe 2p, and Na (Figure S3). The small amount of $\mathrm{Na}$ most likely stems from the base used for delamination while the occurrence of $\mathrm{C}(<$ $5 \%$ ) is attributed to the deposition of adventitious hydrocarbons. Figure 5 shows the $\mathrm{O} 1 \mathrm{~s}$ spectrum of SSI. The O 1s spectrum has been fitted according to Mullet et al. ${ }^{54}$ comprising three oxygen contributions: (i) lattice oxygen $\left(\mathrm{O}^{2-}\right)$ that binds to iron detected at $529.3 \mathrm{eV}$, (ii) oxygen in hydroxyl groups $\left(\mathrm{OH}^{-}, 530.8 \mathrm{eV}\right)$ that binds to iron, and (iii) oxygen present in water $\left(\mathrm{H}_{2} \mathrm{O}, 532.3 \mathrm{eV}\right)$. The 
occurrence of $\mathrm{O}^{2-}$ provides direct evidence for deprotonation of the hydroxyl groups when $\mathrm{Fe}^{\mathrm{II}}$ is oxidized to $\mathrm{Fe}^{\mathrm{III}}$, as also reported by Génin et al. ${ }^{55}$ and Huang et al. ${ }^{56}$. Based on XPS, the ratio of $\mathrm{O}^{2-}$ $/ \mathrm{OH}^{-}$for SSI is 0.71 (Table $\mathrm{S} 1$ ), which is close to the ratio derived from chemical analysis (0.6) and for oxidized $\mathrm{GR}_{\mathrm{C} 12}(0.68)^{12}$, but different from that of 2 line-ferrihydrite (1.34) from this study. The absence of $\mathrm{Cl}^{-}$anions in SSI is significantly different from akaganéite, in which $\mathrm{Cl}^{-}$ions is an essential element of the structure. ${ }^{47}$

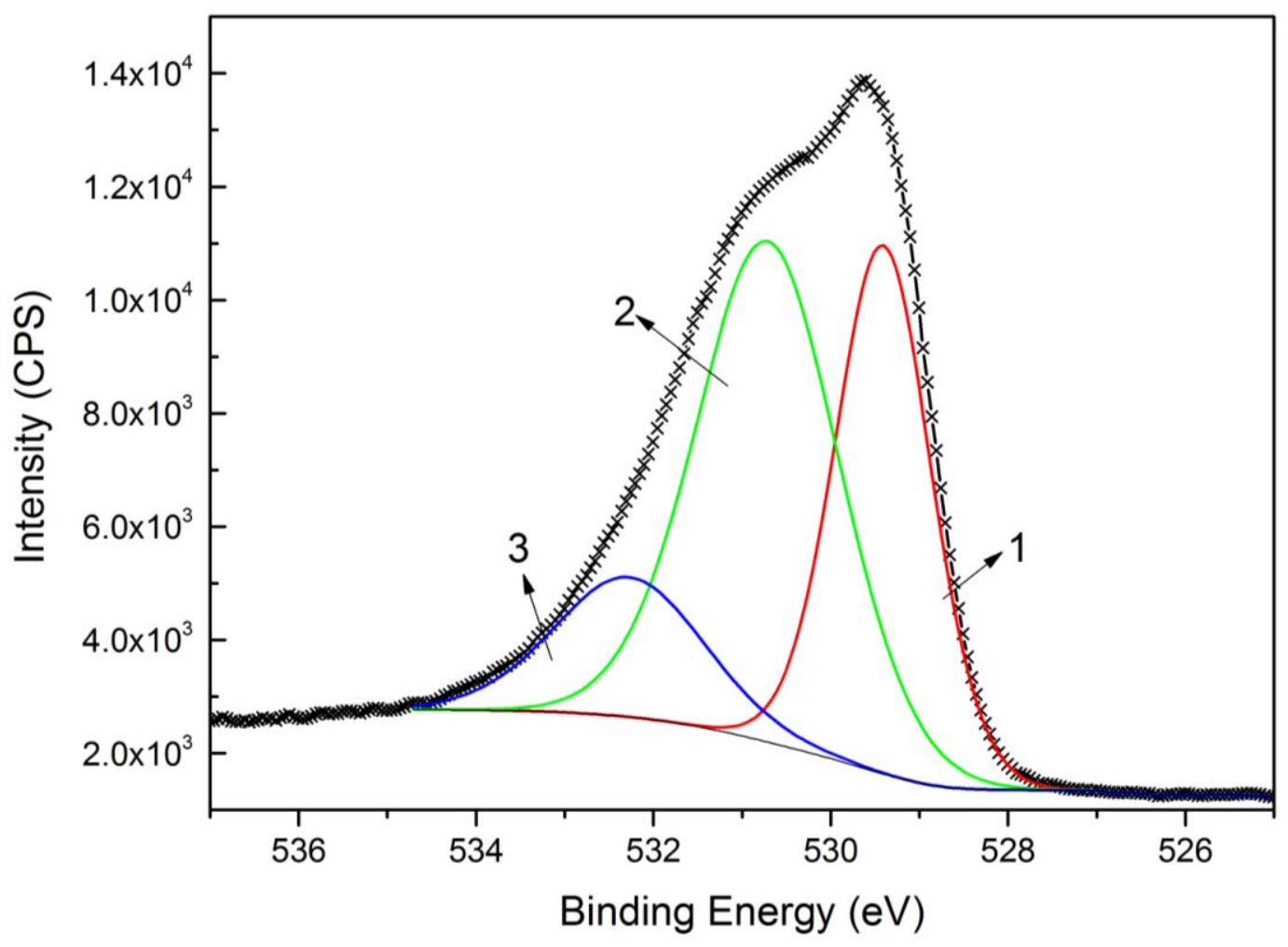

Figure 5. High-resolution oxygen 1s spectrum of SSI. The spectrum was fitted with three peaks: peak 1 corresponds to the oxygen in $\mathrm{O}^{2-}$, peak 2 to oxygen in $\mathrm{OH}^{-}$, and peak 3 to oxygen present in $\mathrm{H}_{2} \mathrm{O}$. The ratio of oxygen present in these three groups is $\mathrm{O}^{2-}: \mathrm{OH}^{-}: \mathrm{H}_{2} \mathrm{O}=35: 50: 15$.

\subsection{Local atomic arrangement}

\subsubsection{Mössbauer Spectroscopy}

Mössbauer spectra of SSI were collected from RT to $9 \mathrm{~K}$ to enable thorough comparison of the results with those for other $\mathrm{Fe}^{\mathrm{III}}$ hydroxides such as 2 line-ferrihydrite or feroxyhite (Figure 6). The spectrum for SSI at room temperature shows a quadrupole doublet which is fitted with a distribution of quadrupole splittings (Table 1). The isomer shift $\left(\delta=0.31 \mathrm{~mm} \mathrm{~s}^{-1}\right)$ indicates the presence of Fe ${ }^{\mathrm{III}}$ 
of SSI is in an octahedral coordination environment ${ }^{57}$. SSI at room temperature shows a paramagnetic behavior with hyperfine parameters similar to those of oxidized GR. ${ }^{40}$ However, the hyperfine parameters at room temperature cannot be used to distinguish SSI from other $\mathrm{Fe}^{\mathrm{III}}$ hydroxides. Between 150 and $77 \mathrm{~K}$, a significant change induced by the decrease of the thermal relaxation is observed resulting in spectra with asymmetrically broadened sextets and a small remaining paramagnetic doublet ( 2 to $4 \%$ ). Spectra show a gradual evolution from quadrupole doublet and broad sextets to a superposition of six-line spectra at $130 \mathrm{~K}$. Mössbauer spectrum measured at $9 \mathrm{~K}$ consists of well-developed sextets, demonstrating that the SSI is magnetically ordered at this temperature. The $9 \mathrm{~K}$ spectrum can be fitted by a distribution of three hyperfine fields of $426 \mathrm{kOe}, 467 \mathrm{kOe}$ and $476 \mathrm{kOe}$ (Table 1), indicating three distinct $\mathrm{Fe}^{\mathrm{III}}$ coordination environments in SSI.

Comparing the spectrum of SSI at low temperature $(9 \mathrm{~K})$ with those of the reference $\mathrm{Fe}^{\mathrm{III}}$ hydroxides, one can see that the low-temperature measurements eliminate all relaxation effects. For SSI the temperature for onset of magnetic ordering is at about $100 \mathrm{~K}$, which is higher than for 2-line ferrihydrite. The temperature for magnetic ordering for synthetic 2-line ferrihydrite ranges from 54 $\mathrm{K}$ for a sample with an average particle size of about $6 \mathrm{~nm}^{58}$ to $45 \mathrm{~K}$ for a sample about $5 \mathrm{~nm}$ in size $^{59}$ and $10.5 \mathrm{~K}$ for a sample $2.8 \mathrm{~nm}$ in $\operatorname{size}^{59}$. At $9 \mathrm{~K}$, the external peaks for the 2-line ferrihydrite are within the range defined by the vertical dashes corresponding to the external peak of SSI (Figure 6). Besides, the spectrum of 2-line ferrihydrite can be fitted by one hyperfine field with a much smaller field strength $(378 \mathrm{kOe})$ and asymmetrical broad lines resulting in weaker magnetic interactions than for SSI in agreement with its lower magnetic ordering and poor crystallinity. In the spectrum of synthetic feroxyhite, one of the fitted hyperfine fields in feroxyhite is distinctly higher than $500 \mathrm{kOe}$, which is consistent with other studies ${ }^{60-64}$. On the contrary, the three fitted hyperfine fields of SSI are all lower than $500 \mathrm{kOe}$. Therefore, the obtained SSI is different from ferrihydrite and feroxyhite.

At room temperature, the Mössbauer spectra of bulk goethite consist of six Lorentzian shape sharp or broadened peaks, depending on factors like crystal size, isomorphous substitution, the content of excess water and vacancies. ${ }^{65,66}$ Goethite with particle sizes below about 15-20 nm are superparamagnetic at room temperature, and goethite smaller than $8 \mathrm{~nm}$ are superparamagnetic at $77 \mathrm{~K} .{ }^{67}$ A survey of 256 soil goethite samples from various localities around the world indicated of mean coherence lengths perpendicular to 110 of $15-20 \mathrm{~nm}$, and thus goethite formed under ambient 
361 conditions are usually superparamagnetic at room temperature. ${ }^{68,69}$ Murad $^{70}$ has shown that a 362 distinction of coexisting goethite from ferrihydrite or feroxyhite using Mössbauer spectra is 363 possible, due to the isomer shift $(\delta=0.37 \mathrm{~mm} / \mathrm{s})$ and quadrupole splitting $(\Delta=-0.25 \mathrm{~mm} / \mathrm{s})$ of 364 goethite at room temperature. Mørup et $\mathrm{al}^{71}$ have shown that the quadrupole coupling constant $\varepsilon(\Delta$ $365=2 \varepsilon)$ is $-0.12 \pm 0.02 \mathrm{~mm} / \mathrm{s}$ at all temperature for both well crystallized and microcrystalline goethite. 366 For comparison, the spectrum of SSI does not show a sextet at room temperature, neither does it 367 show quadrupole splitting $(\Delta)$ of $-0.25 \mathrm{~mm} / \mathrm{s}$ at any temperature in any of the fitted components. 368 Therefore, the goethite impurity observed by XRD in the obtained SSI products could be under the 369 detection limit of Mössbauer spectroscopy. 


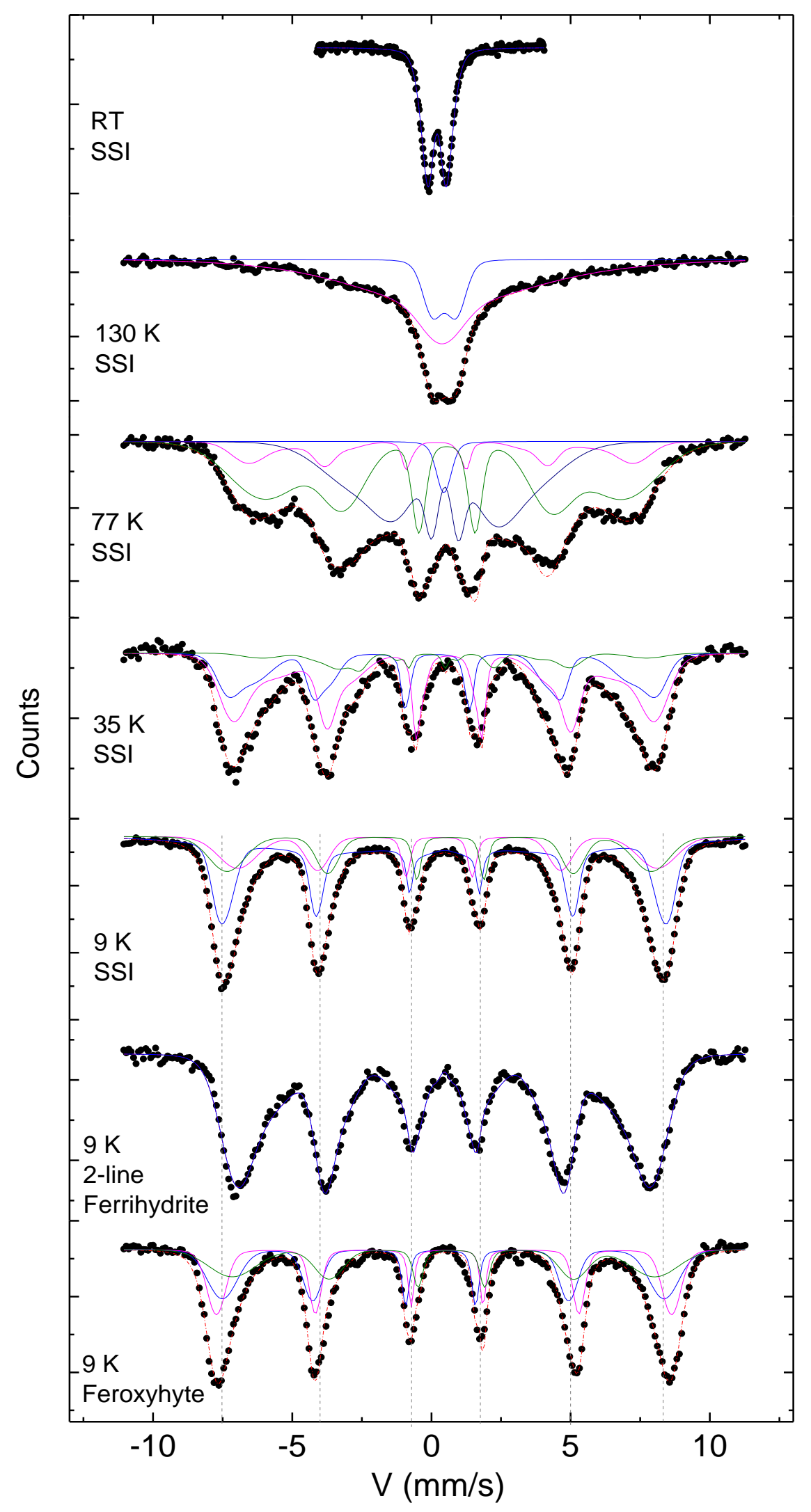


Figure 6. Mössbauer spectra of SSI obtained at different temperatures together with $9 \mathrm{~K}$ spectra of reference $\mathrm{Fe}^{\mathrm{III}}$ hydroxides, 2-line ferrihydrite and feroxyhite. Data is represented by black dots and 373 lines are due to fitting (parameters in Table 1).

374 Table 1. Mössbauer parameters of SSI and other Fe ${ }^{\mathrm{III}}$ hydroxides

\begin{tabular}{|c|c|c|c|c|c|c|}
\hline Sample & $\mathrm{T}(\mathrm{K})$ & $\delta^{\mathrm{a}}(\mathrm{mm} / \mathrm{s})$ & $\Delta^{\mathrm{b}}(\mathrm{mm} / \mathrm{s})$ & $H^{\mathrm{c}}(\mathrm{kOe})$ & $\mathrm{RA}^{\mathrm{d}}(\%)$ & Ref \\
\hline \multirow[t]{13}{*}{ SSI } & 300 & 0.31 & 0.73 & & & \multirow{13}{*}{$\begin{array}{l}\text { This } \\
\text { study }\end{array}$} \\
\hline & \multirow[t]{2}{*}{130} & 0.46 & 0.89 & & 20 & \\
\hline & & 0.48 & 0.19 & 219 & 80 & \\
\hline & \multirow[t]{4}{*}{77} & 0.45 & 0.36 & & 3 & \\
\hline & & 0.25 & 0.08 & 405 & 11 & \\
\hline & & 0.5 & -0.05 & 395 & 48 & \\
\hline & & 0.42 & -0.06 & 185 & 38 & \\
\hline & \multirow[t]{3}{*}{35} & 0.3 & 0.08 & 445 & 33 & \\
\hline & & 0.53 & -0.09 & 432 & 57 & \\
\hline & & 0.33 & 0.48 & 317 & 10 & \\
\hline & \multirow[t]{3}{*}{9} & 0.46 & -0.01 & 426 & 53 & \\
\hline & & 0.42 & 0.15 & 467 & 23 & \\
\hline & & 0.47 & -0.2 & 473 & 24 & \\
\hline \multirow[t]{2}{*}{ Goethite } & 295 & 0.37 & -0.26 & 380 & & \multirow[t]{2}{*}{72} \\
\hline & 4.2 & 0.48 & -0.25 & 506 & & \\
\hline \multirow{2}{*}{$\begin{array}{l}\text { 2-line } \\
\text { ferrihydrite }\end{array}$} & 300 & 0.24 & 0.79 & & & \multirow{2}{*}{$\begin{array}{l}\text { This } \\
\text { study }\end{array}$} \\
\hline & 9 & 0.46 & -0.03 & 378 & & \\
\hline \multirow{3}{*}{$\begin{array}{l}\text { 6-line } \\
\text { ferrihydrite }\end{array}$} & 292 & 0.24 & 0.72 & 472 & & \multirow[t]{3}{*}{25} \\
\hline & 4.2 & 0.5 & -0.03 & 505 & 61 & \\
\hline & & 0.42 & -0.04 & 471 & 39 & \\
\hline \multirow[t]{4}{*}{ Feroxyhite } & 295 & 0.37 & -0.06 & & & \multirow{4}{*}{$\begin{array}{l}\text { This } \\
\text { study }\end{array}$} \\
\hline & \multirow[t]{3}{*}{10} & 0.38 & 0.05 & 492 & 37 & \\
\hline & & 0.51 & -0.06 & 507 & 32 & \\
\hline & & 0.58 & -0.14 & 471 & 31 & \\
\hline Oxidized & \multirow[t]{4}{*}{9} & 0.5 & -0.07 & 497 & 33.5 & \multirow[t]{4}{*}{40} \\
\hline \multirow[t]{3}{*}{$\mathrm{GR}_{\mathrm{Cl}}$} & & 0.49 & -0.1 & 469 & 28.5 & \\
\hline & & 0.50 & -0.12 & 441 & 23.5 & \\
\hline & & 0.48 & -0.06 & 401 & 14.6 & \\
\hline
\end{tabular}

$375{ }^{\mathrm{a}}$ Isomer shift relative to $\alpha$-iron at room temperature; ${ }^{\mathrm{b}}$ Quadrupole splitting or shift; ${ }^{\mathrm{c}}$ Hyperfine 376 field; ${ }^{\mathrm{d}}$ relative abundance. The accuracy is $\pm 0.02 \mathrm{~mm} / \mathrm{s}$ for the isomer shift $\delta$ and the quadrupole 377 splitting $\Delta$ and $\pm 5 \mathrm{kOe}$ for the hyperfine field $H$. 
High energy X-ray scattering data were obtained to determine the local and medium range structure with pair distribution function analysis. The $I(Q)$ and $G(r)$ for the materials examined are shown in Figure 7 and the d values for main peaks, in Table S2.

The $\mathrm{I}(\mathrm{Q})$ for the $\mathrm{GR}_{\mathrm{Cl}}$ starting material displays peaks with positions very similar to those reported for this phase. ${ }^{73}$ For example, the peak at $\mathrm{Q}=0.79 \AA^{-1}$ represents the $\sim 7.95 \AA$ basal plane distance in $\mathrm{GR}_{\mathrm{Cl}}$. For the first $10 \AA$ of the corresponding PDF (Figure 7), peak positions and intensities greatly resemble those reported for Na-bearing $\mathrm{GR}_{\mathrm{SO} 4}{ }^{22}$ The first clear peak at $\mathrm{r} \approx 2.10$ $\AA$ represents the first neighbor Fe-O pairs. The second peak at $\mathrm{r} \approx 3.20 \AA$ corresponds with second neighbor Fe-Fe pairs in edge-sharing octahedra. Notably, the peak intensities decay considerably as r-values increase above $10 \AA$, showing that the material has coherent scattering domains of relatively small average size (below the instrumental envelope of $\sim 8 \mathrm{~nm}$ ). Also, the pattern largely lacks the peaks for correlations of electron dense Fe-Fe atomic pairs across interlayers. Inspection of the structure given for fougerite, ${ }^{74}$ which is based on XRD of synthetic $\mathrm{GR}_{\mathrm{Cl}}$, and calculations of the expected PDF with PDFGUI shows that correlations of Fe-Fe pairs across interlayers should give rise to peaks at $r$ values of $8.76 \AA$ (coordination number, $\mathrm{CN}$, of 6 ) and $9.32 \AA$ (CN of 12 ). The measured intensity for these peaks is much smaller than expected from calculations (Figure 6), albeit basal plane reflections are clear in the XRD and the $\mathrm{I}(\mathrm{Q})$. This indicates that the $\mathrm{GR}_{\mathrm{Cl}}$ synthesized here has small coherent scattering domain in general as well as turbostratic disorder.

Upon intercalation of dodecanoate, the basal plane reflection of $\mathrm{GR}_{\mathrm{Cl}}$ at $\mathrm{Q}=0.79 \AA^{-1}$ is markedly decreased in intensity. Moreover, new peaks develop in the low $\mathrm{Q}$ region as would be expected from a change in the interlayer distance between $\mathrm{Fe}^{\mathrm{II}}-\mathrm{Fe}^{\mathrm{III}}$ hydroxide layers. In contrast, the PDF for the $\mathrm{C} 12$ intercalated GR is practically identical to the pattern for $\mathrm{GR}_{\mathrm{Cl}}$, showing that the $\mathrm{Fe}^{\mathrm{II}}-\mathrm{Fe}^{\mathrm{III}}$ hydroxide layers remain intact during intercalation. The pattern for the $\mathrm{GR}_{\mathrm{C} 12}$ does show a slight shifting of peaks to lower $r$ values compared to $\mathrm{GR}_{\mathrm{Cl}}$. The magnitude of the shift increases with the interatomic distance of the peak. Possibly, the shift arises from contraction of the structure in response to slight oxidation of $\mathrm{Fe}^{\mathrm{II}}$.

Oxidation of the $\mathrm{GR}_{\mathrm{C} 12}$ produces substantial changes in the $\mathrm{I}(\mathrm{Q})$, which now shows only three broad peaks. The first peak varies in $\mathrm{Q}$ value from 1.40 to $1.47 \AA^{-1}$ for the two samples, whereas the last two peaks are invariably placed at 2.47 and $4.24 \AA^{-1}$. Consistent with the broadness of the peaks, the PDFs decay extensively with $r$ and display only minor oscillations above $40 \AA$ (Figure 7). Inspection of the PDFs at $r<10 \AA$ shows that the oxidation step has produced significant changes 
in local and medium range structure. The first peak, which has contributions largely from Fe-O pairs, has decreased in $\mathrm{r}$ from $\sim 2.10 \AA$ to $1.98 \AA$, reflecting the smaller ionic radii of oxidized $\mathrm{Fe}^{\mathrm{III}} \cdot{ }^{75}$ In addition, the patterns display two peaks at $\mathrm{r}=3.03 \AA$ and $\sim 3.41 \AA$ that largely represent $\mathrm{Fe}-\mathrm{Fe}$ atomic pairs (marked with dotted lines in Figure 7). This shows that the brucite-like hydroxide layer with its equidistant, edge sharing Fe has restructured.

The positions of the two peaks for Fe-Fe in oxidized $\mathrm{GR}_{\mathrm{C} 12}$ resemble those for pairs with edge and corner-sharing polyhedra in goethite (3.02 and 3.40 $\AA$ ) and ferrihydrite (3.04 and 3.44 $\mathrm{A}$ ), but differ from those for synthetic feroxyhite (3.00 and 3.50 $\AA$, with a shoulder of significant intensity at $\sim 3.76 \AA$ ). At larger $r$ values, the peaks for the oxidized $\mathrm{GR}_{\mathrm{C} 12}$ variably are similar to those for ferrihydrite, feroxyhite and goethite. Fitting with PDFGui of ferrihydrite ${ }^{76}$ and goethite structures ${ }^{38}$ to the data yield a relatively good match (Figure 8A). However, the fitted ferrihydrite structure is distorted with cell lengths of $\mathrm{a}=6.03$ and $\mathrm{c}=8.85 \AA$ and it contains only $25 \%$ occupancy for the $\mathrm{Fe}_{2}$ site. For the fitted goethite structure, the $\sim 1 \mathrm{~nm}$ size of the coherent scattering domains is exceptionally small. Given that the fitted phases are so unusual in structure, we find it unlikely that they represent separate, distinct phases in the oxidized $\mathrm{GR}_{\mathrm{C} 12}$ samples. Rather, we interpret that the oxidized $\mathrm{GR}_{\mathrm{C} 12}$ contains motifs that resemble those of ferrihydrite and goethite.

Ferrihydrite, feroxyhite and goethite are closely related in structure to GR, all containing layers of edge-sharing octahedra. For the $\mathrm{Fe}^{\mathrm{III}}$ hydroxides the octahedra are partially occupied by Fe, and they are linked to the polyhedra of other layers via corner sharing. In addition, the formation of ferrihydrite and goethite requires the only dislocation of a subset of the edge-sharing Fe octahedra in the GR into its interlayers, and collapse of the interlayer to form the three-dimensional structures. In combination with our observations, this suggests that oxidation of the $\mathrm{GR}_{\mathrm{C} 12}$ results in dislocation of $\mathrm{Fe}$ into the interlayers produce a bi- or tri-layered $\mathrm{Fe}^{\mathrm{III}}$ hydroxide, with $\mathrm{Fe}$ linkage through both corner and edge-sharing polyhedra. Notably, a tri-layered model would have a thickness of $\sim 1 \mathrm{~nm}$, similar to that observed for the SSI.

To probe this hypothesis, a model molecule based on a $4 \mathrm{~nm}$ wide $\mathrm{Fe}^{\mathrm{III}}$ hydroxide layer with 121 $\mathrm{Fe}$ atoms based on the structure of $\mathrm{Fe}(\mathrm{OH})_{2}{ }^{77}$ was fitted to the scattering data using DiffPy-CMI. Two types of starting configurations were tested: one where all Fe resided initially in a single $\mathrm{Fe}^{\mathrm{III}}$ hydroxide layer (Figure 8B) and one where every fourth Fe atom was displaced $1.8 \mathrm{~nm}$ above or below the Fe ${ }^{\mathrm{III}}$ hydroxide layer in an ordered manner (Figure $8 \mathrm{C}$ ). Subsequently, the structures were fitted in 1000 iterations to minimize the misfit between calculated and measured PDFs using a least 
square optimizer. During each iteration, four Fe atoms were selected randomly and their z-positions were allowed to change alongside the cell dimension of the model and two isotropic atomic displacement parameters for $\mathrm{Fe}$ and $\mathrm{O}$. After this first fitting, $\mathrm{O}$ atoms were added within an ABAB packing scheme to the displaced $\mathrm{Fe}$ and another iterative fit was performed.

The calculated PDFs and an example of the resulting molecule are shown in Figure 8D. Considering the simplicity of the model, the calculated PDFs agree well with the overall peak positions and intensities that were measured. However, significant misfits exist. The peak at $\sim 5.5 \AA$, for example, is particularly intense in the PDF for goethite. Here, it represents to a large degree second neighbor Fe-Fe distances across double chains of octahedrally coordinated Fe atoms that are twisted slightly with respect to each other. The relatively high intensity of the $\sim 5.5 \AA$ peak indicates that this coordination environment, or one resembling it, is likely to be present in the oxidized $\mathrm{GR}_{\mathrm{C} 12}$. Such a coordination environment cannot be achieved with our modeling, given its rigid $\mathrm{O}$ lattice. Similarly, the Fe atoms are not always centered in the octahedra, which could have been achieved for a model allowing moderation of the O lattice. Furthermore, the model does not allow relaxation of $\mathrm{Fe}$ in $\mathrm{x}$ - or $\mathrm{y}$ - dimension, which could produce broadening of higher $\mathrm{r}$ peaks and a better match. Never the less, we conclude that a pattern resembling that measured for the oxidized $\mathrm{GR}_{\mathrm{C} 12}$ can be generated through dislocation of $\mathrm{Fe}$ up and down from the $\mathrm{Fe}^{\mathrm{III}}$ hydroxide layer. Interestingly, up- and downward displacement of $\mathrm{Fe}$ is predicted to occur as a hole (a Fe ${ }^{\mathrm{III}}$ defect) hops as a small polaron through a $\mathrm{Fe}^{\mathrm{II}}(\mathrm{OH})_{2}$ sheet, albeit at smaller length scales. ${ }^{78}$

Upon delamination, the three $\mathrm{I}(\mathrm{Q})$ peaks of the oxidized $\mathrm{GR}_{\mathrm{C} 12}$ sharpen, the peak at $2.47 \AA^{-1}$ becomes asymmetric, and additional peaks appear at $\mathrm{Q}=2.82,3.66$ and $4.00 \AA^{-1}$. These peaks coincide with major reflections for goethite. Consistent with the presence of a small amount of goethite (a couple of percents) (Fig. 1, profile 4), the PDF displays slight increases in the intensities at $r \approx 3.4,5.4$ and $9.4 \AA^{-1}$, where peaks for the synthetic goethite are intense. Thus, we conclude that a slight amount of goethite was produced during the delamination step, but that structural changes to the tri-layer were small. 

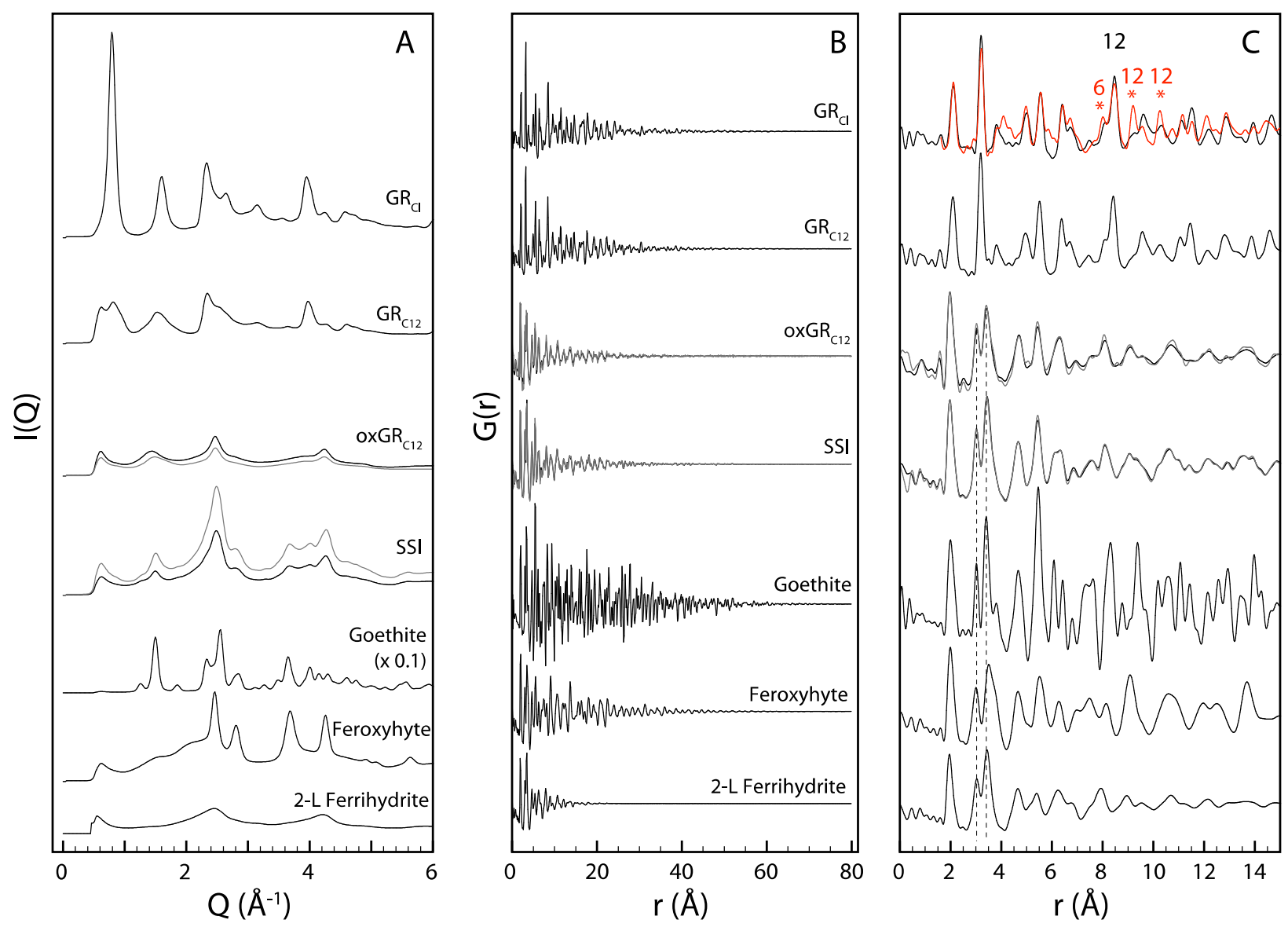

Figure 7. High energy X-ray scattering data for the samples. A) I(Q) in the Q range with clear Bragg reflections $(\mathrm{Q}=2 \pi / \mathrm{d})$.

B) $G(r)$ until $8 \mathrm{~nm}$. The decay of the $G(r)$ at higher $r$ for goethite values is caused largely by the instrumental resolution. C) Zoom of the $G(r)$. The red lines represent

471 calculated patterns after fitting. Numbers above peaks refer to the $\mathrm{CN}$ of $\mathrm{Fe}-\mathrm{Fe}$ atomic pairs within $472 \mathrm{Fe}^{\mathrm{II}}-\mathrm{Fe}^{\mathrm{III}}$ hydroxide layers (black) and in separate $\mathrm{Fe}^{\mathrm{II}}-\mathrm{Fe}^{\mathrm{III}}$ hydroxide layers (red and marked with an asterisk). The dotted lines mark the positions of peaks representing largely Fe-Fe pairs with edge and corner-sharing polyhedral position. 

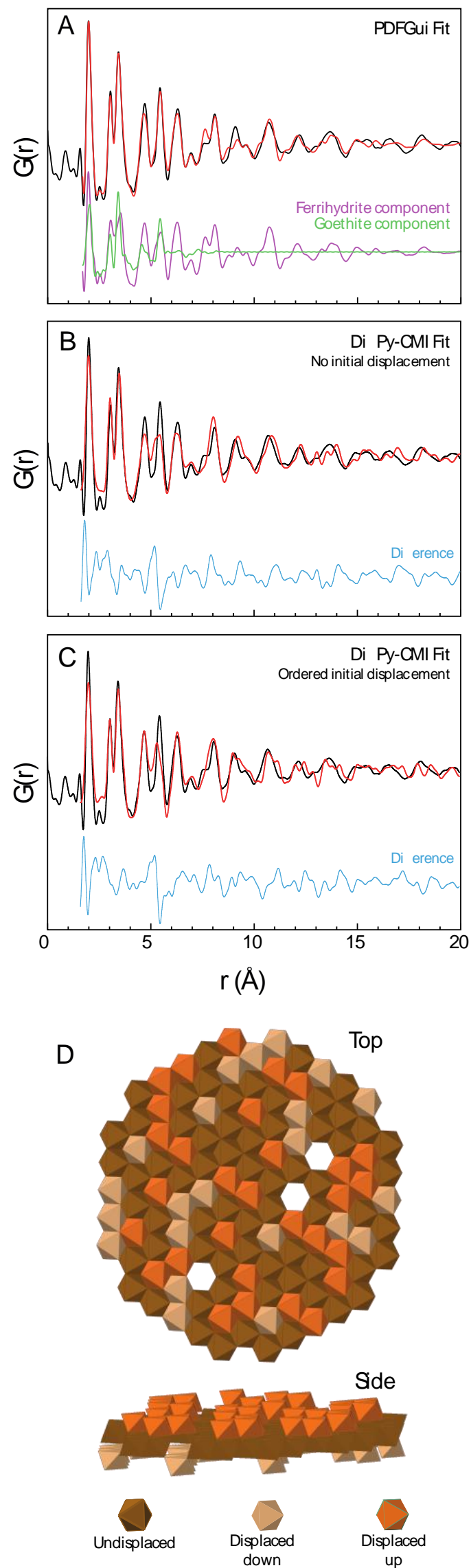
Figure 8. The results of the fitting to the PDF for the SSI. Patterns from fitting with A) PDFGui fit using ferrihydrite and goethite components; B) with DiffPY-CMI using a structure without initial displacement; C) with DiffPY-CMI using a structure with initial ordered displacement and D) An example molecule after fitting. Vacancies represent Fe that has moved more than $2 \AA$ away from the original sheet.

\subsubsection{Comparison with other ultrathin iron oxides}

Not only SSI or ferrihydrite, but also other the iron oxides described above can be synthesized as very small particles, e.g. goethite ${ }^{79}$, hematite, ${ }^{80,81}$ lepidocrocite $^{82}$ and feroxyhite ${ }^{83}$. Thus, thin goethite particles (6.8 $\mathrm{nm}$ thickness corresponding to [110] plane) has been synthesized as part of a goethite/graphene oxide composite ${ }^{79}$. Similarly, 2D ultrathin feroxyhite $(1.1 \mathrm{~nm} \text { thick })^{83}$ and 2D lepidocrocite ${ }^{82}$ ( 2 3 $\mathrm{nm}$ thick) has been synthesized. All of these nano-sized iron oxides show up their typical powder XRD traces demonstrating the presence of coherent scattering domains consisting of at least several atomic layers. In comparison, SSI is amorphous to powder XRD, while Fe atoms in the SSI sheets occur in an ordered and regular pattern. Mössbauer and X-ray scattering analysis indicates that the structure is distinct from other types of $\mathrm{Fe}^{\mathrm{III}}$ hydroxide nanosheets however with some similarity to the structure of feroxyhite. In SSI, only edge and corner-sharing iron octahedra are observed. Interpretation of the feroxyhite structure has given rise to slightly different structural models ${ }^{84,85}$, however, sharing the same features for the local atomic arrangements and comprising both face, edge and corner-sharing iron octahedra, which is consistent with the PDF observed for feroxyhite in the present study (Figure 7). Sestu et al. ${ }^{84}$ proposed a mean structure of feroxyhite based on goethite by assuming that the local structures of feroxyhite contain the same structural elements as for goethite. Thus, conceptually the structures of SSI, goethite and feroxyhite are related and all may form from the brucitic $\mathrm{Fe}^{\mathrm{II}}-\mathrm{Fe}^{\mathrm{III}}$ hydroxide layers of GR, but where SSI represents the least reorganization of iron octahedra in the parent brucitic sheet, while goethite represents the highest reorganization. The synthesis pathway for SSI via $\mathrm{GR}_{\mathrm{C} 12}$ and its oxidation product favors formation of SSI in preference of feroxyhite and goethite. Guyanaite ${ }^{86}$, a precursor to goethite has been reported sharing similar SAED pattern and broad-peaked XRD pattern with SSI. Therefore, SSI may be as a possible metastable intermediate during the formation of feroxyhite and goethite. In $\mathrm{GR}_{\mathrm{C} 12}$ the brucitic $\mathrm{Fe}^{\mathrm{II}}-\mathrm{Fe}^{\mathrm{III}}$ hydroxide layers are "insolated" from neighboring hydroxide layers by dodecanoate interlayers. Thus, during oxidation of the $\mathrm{Fe}^{\mathrm{II}}-\mathrm{Fe}^{\mathrm{III}}$ hydroxide layers no bonding or polymerization can take place between FeIII-O/OH octahedra 
across the interlayers. Hence, structural alterations can only take place in single layers thus giving rise to the formation of separate single layers. Thus, the presence of the dodecanoate interlayer impedes nucleation of feroxyhite or goethite during oxidation.

Compared with other nanosized $\mathrm{Fe}^{\mathrm{III}}$ hydroxides, the delamination and structural alteration of the brucitic metal hydroxide layers in GR to form SSI enhances the surface complexation properties, as the surface hydroxyl groups change from being all triply coordinated at [001] faces to singly, doubly and triply coordinated. Singly coordinated sites have a higher affinity for surface complexation compared with triply coordinated sites in metal hydroxide layer in LDHs ${ }^{65}$. In a previous study, the SSI showed a high sorption capacity for phosphate compared with other LDHs such as Mg-Fe LDH and iron oxides ${ }^{13}$. Therefore, SSI is a promising sorbent material. Besides, SSI may show a high catalytic (e.g. at electro- or photocatalysis) capability compared with other nanosized iron oxides due to particular light absorption, electrical and semiconductor properties. The assembly of SSI with other single sheet materials may also open a new approach to obtain multifunctional nanocomposites.

\section{CONCLUSIONS}

Single sheet iron oxide was successfully obtained as a new two-dimensional material with a structure different from other types of iron oxide. The lack of reflections in the SSI powder XRD trace is consistent with a material lacking three-dimensional long-range order. AFM and TEM showed that SSI consists of thin sheet-like objects with an average height of $1 \mathrm{~nm}$, and with a wellordered hexagonal arrangement in the sheets with an atomic row distance of $\sim 0.28 \mathrm{~nm}$. Based on the chemical and thermal analysis, the composition of SSI was $\mathrm{FeO}_{0.82}(\mathrm{OH})_{1.38} \cdot 0.7 \mathrm{H}_{2} \mathrm{O}$. Magnetically ordered Mössbauer spectra of SSI at 9K could be decomposed into three sextets, with hyperfine parameters distinct from other iron oxides. SSI exhibited similar structural elements with other iron oxides, but different in the detailed analysis. PDF analysis of high-energy X-ray scattering data showed that oxidized $\mathrm{GR}_{\mathrm{C} 12}$ and SSI were characterized by two pairs of $\mathrm{Fe}-\mathrm{Fe}$ nearest neighbors demonstrating that the brucite-type structure of GR with only a single signal for $\mathrm{Fe}-\mathrm{Fe}$ nearest neighbors altered during oxidation. A model with a partial displacement of iron octahedra out of the brucitic $\mathrm{Fe}^{\mathrm{II}}-\mathrm{Fe}^{\mathrm{III}}$ hydroxide layer results in a calculated PDF that agrees reasonably with the measured pattern. Thus, during oxidation, the GR structure with entire edgesharing of iron octahedra transformed to SSI comprising both edge and corner-sharing octahedra. The synthesis pathway via $\mathrm{GR}_{\mathrm{C} 12}$ is critical for the formation of SSI as the "insolating" C12 
540 interlayer hinders bonding and polymerization between $\mathrm{Fe}^{\mathrm{III}}-\mathrm{O} / \mathrm{OH}$ octahedra across interlayers 541 during oxidation and thus only structural reorganizations of single brucitic $\mathrm{Fe}^{\mathrm{II}}-\mathrm{Fe}^{\mathrm{III}}$ hydroxide 542 layers can take place during oxidation.

\section{AUTHOR INFORMATION}

\section{Corresponding Author}

546 *E-mail: yin@ @len.ku.dk

\section{$547 \quad$ Notes}

548 The authors declare no competing financial interest.

\section{ACKNOWLEDGMENT}

550 We are thankful for the kind assistance provided by Karina Chapman, Rick Spence, and Kevin A. 551 Beyer at APS beamline 11 ID-B. Use of the Advanced Photon Source was supported by the U.S. 552 Department of Energy, Office of Science, Office of Basic Energy Sciences, under Contract No. DE553 AC02-06CH11357. The Danish Council for Independent Research (via DANSCATT) provided 554 support for travel to the synchrotron facility. We are thankful for Martine Mallet, Laboratoire de 555 Chimie Physique et Microbiologie, Université de Lorraine and Center of Modern Analysis and 556 Nanjing University. We also want to give our gratitude to the financial support of the University of 557 Copenhagen and China Scholarship Council.

\section{REFERENCES}

559 (1) Cavani, F.; Trifirò, F.; Vaccari, A. Hydrotalcite-Type Anionic Clays: Preparation, Properties and 560

(2) Braterman, P. S.; Xu, Z. P.; Yarberry, F. Layered Double Hydroxides (LDHs). Handb. Layer. Mater. 2004, 26 (2), 373-474.

563 (3) Song, F.; Hu, X. Exfoliation of Layered Double Hydroxides for Enhanced Oxygen Evolution

(4) Li, L.; Ma, R.; Ebina, Y.; Iyi, N.; Sasaki, T. Positively Charged Nanosheets Derived via Total 
Synthesis of Colloidal Nickel-Manganese Layered Double Hydroxide Nanosheets and Their Pseudocapacitive Properties. Chem. - A Eur. J. 2014, 20 (45), 14880-14884.

(6) Meyn, M.; Beneke, K.; Lagaly, G. Anion-Exchange Reactions of Layered Double Hydroxides. Inorg. Chem. 1990, 29 (26), 5201-5207.

(7) Yu, J.; Liu, J.; Clearfield, A.; Sims, J. E.; Speiegle, M. T.; Suib, S. L.; Sun, L. Synthesis of Layered Double Hydroxide Single-Layer Nanosheets in Formamide. Inorg. Chem. 2016, 55 (22), 12036 12041.

(8) Naik, V. V.; Vasudevan, S. Sol-Gel Transition in Dispersions of Layered Double-Hydroxide Nanosheets. Langmuir 2011, 27 (21), 13276-13283.

(9) Leroux, F.; Adachi-Pagano, M.; Intissar, M.; Chauvière, S.; Forano, C.; Besse, J.-P. Delamination and Restacking of Layered Double Hydroxides. J. Mater. Chem. 2001, 11 (1), 105-112.

(10) Funnell, N. P.; Wang, Q.; Connor, L.; Tucker, M. G.; O’Hare, D.; Goodwin, A. L. Structural Characterisation of a Layered Double Hydroxide Nanosheet. Nanoscale 2014, 6 (14), 8032-8036.

(11) Harrington, R.; Hausner, D. B.; Bhandari, N.; Strongin, D. R.; Chapman, K. W.; Chupas, P. J.; Middlemiss, D. S.; Grey, C. P.; Parise, J. B. Investigation of Surface Structures by Powder Diffraction: A Differential Pair Distribution Function Study on Arsenate Sorption on Ferrihydrite. Inorg. Chem. 2010, 49 (1), 325-330.

(12) Huang, L.; Fang, L.; Hassenkam, T.; Dalby, K. N.; Scheckel, K. G.; Hansen, H. C. B. A One-Step Delamination Procedure to Form Single Sheet Iron(iii)-(Oxy)hydroxides. J. Mater. Chem. A 2013, 1 (43), 13664.

(13) Fang, L.; Huang, L.; Holm, P. E.; Yang, X.; Hansen, H. C. B.; Wang, D. Facile Upscaled Synthesis of Layered Iron Oxide Nanosheets and Their Application in Phosphate Removal. J. Mater. Chem. A 2015, 3 (14), 7505-7512.

(14) Huang, L.-Z.; Hassenkam, T.; Hansen, H. C. B.; Bjerrum, M. J. Single Sheet Iron Oxide Based Films: Electrochemical Properties with in Situ UV-Vis Measurement. J. Mater. Chem. A 2014, 2 (11), 4029.

(15) Huang, L.; Hansen, H. C. B.; Bjerrum, M. J. Electrochemical Reduction of Nitroaromatic Compounds by Single Sheet Iron Oxide Coated Electrodes. J. Hazard. Mater. 2016, 306, 175-183.

(16) Schwertmann, U.; Cornell, R. The Iron Oxides in the Laboratory, 2nd ed.; Wiley-VCH Verlag GmbH \& Co. KGaA, 2000.

(17) Legrand, L.; Mazerolles, L.; Chaussé, A. The Oxidation of Carbonate Green Rust into Ferric Phases: Solid-State Reaction or Transformation via Solution. Geochim. Cosmochim. Acta 2004, 68 (17), $3497-3507$.

(18) Wang, X.; Liu, F.; Tan, W.; Feng, X.; Koopal, L. K. Transformation of Hydroxycarbonate Green 
Rust into Crystalline Iron (Hydr)oxides: Influences of Reaction Conditions and Underlying Mechanisms. Chem. Geol. 2013, 351, 57-65.

(19) Michel, F. M.; Ehm, L.; Antao, S. M.; Lee, P. L.; Chupas, P. J.; Liu, G.; Strongin, D. R.; Schoonen, M. A. A.; Phillips, B. L.; Parise, J. B. The Structure of Ferrihydrite, a Nanocrystalline Material. Science 2007, 316 (5832), 1726-1729.

(20) Drits, V. A. Structure of Feroxyhite as Determined by Simulation of X-Ray Diffraction Curves. Clay Miner. 1993, 28 (2), 209-222.

(21) Ghose, S. K.; Waychunas, G. a.; Trainor, T. P.; Eng, P. J. Hydrated Goethite ( $\alpha-\mathrm{FeOOH})(100)$ Interface Structure: Ordered Water and Surface Functional Groups. Geochim. Cosmochim. Acta 2010, 74 (7), 1943-1953.

(22) Christiansen, B. C.; Dideriksen, K.; Katz, A.; Nedel, S.; Bovet, N.; Sørensen, H. O.; Frandsen, C.; Gundlach, C.; Andersson, M. P.; Stipp, S. L. S. Incorporation of Monovalent Cations in Sulfate Green Rust. Inorg. Chem. 2014, 53 (17), 8887-8894.

(23) Hansen, H. C. B.; Koch, C. B. Reduction of Nitrate to Ammonium by Sulphate Green Rust: Activation Energy and Reaction Mechanism. Clay Miner. 1998, 33 (1), 87-101.

(24) Yin, W.; Strobel, B. W.; Hansen, H. C. B. Amino Acid-Assisted Dehalogenation of Carbon Tetrachloride by Green Rust: Inhibition of Chloroform Production. Environ. Sci. Technol. 2017, 51 (6), 3445-3452.

(25) Pollard, R. J. Characterization of FeOOH Polymorphs and Ferrihydrite Using Low-Temperature, Applied-Field, Mössbauer Spectroscopy. Clay Miner. 1992, 27 (1), 57-71.

(26) Patterson, A. L. The Scherrer Formula for X-Ray Particle Size Determination. Phys. Rev. 1939, 56 (10), 978-982.

(27) Rancourt, D. G.; Ping, J. Y. Voigt-Based Distributions Methods for Arbitrary-Shape in Mössbauer Spectroscopy Static Hyperfine Parameter. Nucl. Instruments Methods Phys. Res. B 1991, 58 (1), 8597.

(28) Dideriksen, K.; Frandsen, C.; Bovet, N.; Wallace, A. F.; Sel, O.; Arbour, T.; Navrotsky, A.; De Yoreo, J. J.; Banfield, J. F. Formation and Transformation of a Short Range Ordered Iron Carbonate Precursor. Geochim. Cosmochim. Acta 2015, 164, 53-70.

(29) Hammersley, A. P.; Svensson, S. O.; Thompson, A. Calibration and Correction of Spatial Distortions in 2D Detector Systems. Nucl. Instruments Methods Phys. Res. Sect. A Accel. Spectrometers, Detect. Assoc. Equip. 1994, 346 (1-2), 312-321.

(30) Hammersley, A. FIT2D: An Introduction and Overview; Grenoble, France, 1997.

(31) Chupas, P. J.; Qiu, X.; Hanson, J. C.; Lee, P. L.; Grey, C. P.; Billinge, S. J. L. Rapid-Acquisition Pair 
Distribution Function (RA-PDF) Analysis. J. Appl. Crystallogr. 2003, 36 (6), 1342-1347.

(32) Qiu, X.; Thompson, J. W.; Billinge, S. J. L. PDFgetX2 : A GUI-Driven Program to Obtain the Pair Distribution Function from X-Ray Powder Diffraction Data. J. Appl. Crystallogr. 2004, 37 (4), 678678.

(33) Takeshi, E.; Billinge, S. J. L. Chapter 1 - Structure of Complex Materials. In Underneath the Bragg Peaks Structural Analysis of Complex Materials; 2012; Vol. Volume 16, pp 1-25.

(34) Farrow, C. L.; Juhas, P.; Liu, J. W.; Bryndin, D.; Božin, E. S.; Bloch, J.; Proffen, T.; Billinge, S. J. L. PDFfit2 and PDFgui: Computer Programs for Studying Nanostructure in Crystals. J. Phys. Condens. Matter 2007, 19 (33), 335219.

(35) Juhás, P.; Farrow, C. L.; Yang, X.; Knox, K. R.; Billinge, S. J. L. Complex Modeling: A Strategy and Software Program for Combining Multiple Information Sources to Solve Ill Posed Structure and Nanostructure Inverse Problems. Acta Crystallogr. Sect. A Found. Adv. 2015, 71 (6), 562-568.

(36) Farrow, C. L.; Bediako, D. K.; Surendranath, Y.; Nocera, D. G.; Billinge, S. J. L. Intermediate-Range Structure of Self-Assembled Cobalt-Based Oxygen-Evolving Catalyst. J. Am. Chem. Soc. 2013, 135 (17), 6403-6406.

(37) Beecher, A. N.; Yang, X.; Palmer, J. H.; Lagrassa, A. L.; Juhas, P.; Billinge, S. J. L.; Owen, J. S. Atomic Structures and Gram Scale Synthesis of Three Tetrahedral Quantum Dots. J. Am. Chem. Soc. 2014, 136 (30), 10645-10653.

(38) Hoppe, W. Über Die Kristallstruktur von Alpha-AlOOH (Diaspore) Und Alpha-FeOOH (Nadeleisenerz). Z. Krist. 1940, 103, 73-89.

(39) Hansen, H. Kinetics of Nitrate Reduction by Green Rusts - effects of Interlayer Anion and Fe(II):Fe(III) Ratio. Appl. Clay Sci. 2001, 18 (1-2), 81-91.

(40) Refait, P.; Benali, O.; Abdelmoula, M.; Génin, J. M. R. Formation of "Ferric Green Rust" And/or Ferrihydrite by Fast Oxidation of iron(II-III) Hydroxychloride Green Rust. Corros. Sci. 2003, 45 (11), 2435-2449.

(41) O'Loughlin, E. J.; Kemner, K. M.; Burris, D. R. Effects of Ag I , Au III , and Cu II on the Reductive Dechlorination of Carbon Tetrachloride by Green Rust. Environ. Sci. Technol. 2003, 37 (13), 29052912.

(42) Choi, J.; Batchelor, B.; Chung, J. Reductive Dechlorination of Tetrachloroethylene by Green Rusts Modified with Copper. Water. Air. Soil Pollut. 2010, 212 (1-4), 407-417.

(43) Ayala-Luis, K. B.; Koch, C. B.; Hansen, H. C. B. Intercalation of Linear C9-C16 Carboxylates in Layered FeII-FeIII-Hydroxides (Green Rust) via Ion Exchange. Appl. Clay Sci. 2010, 48 (3), 334-341.

(44) Kang, H.; Huang, G.; Ma, S.; Bai, Y.; Ma, H.; Li, Y.; Yang, X. Coassembly of Inorganic 
Macromolecule of Exfoliated LDH Nanosheets with Cellulose. J. Phys. Chem. C 2009, 113 (21), 9157-9163.

(45) Alansi, A. M.; Alkayali, W. Z.; Al-qunaibit, M. H.; Qahtan, T. F.; Saleh, T. A. Synthesis of Exfoliated Polystyrene/anionic Clay MgAl-Layered Double Hydroxide: Structural and Thermal Properties. RSC Adv. 2015, 5 (87), 71441-71448.

(46) Cambier, P. Infrared Study of Goethites of Varying Crystallinity and Particle Size: I. Interpretation of OH and Lattice Vibration Frequencies. Clay Miner. 1986, 21 (2), 191-200.

(47) Cornell, R. M.; Schwertmann, U. The Iron Oxides: Structure, Properties, Reactions, Occurrences and Uses. Techniques 2003, 39 (8), 9-12.

(48) Christian, H.; Hansen, B.; Poulsen, I. F. Interaction of Synthetic Sulphate Green Rust with Phosphate and the Crystallization of Vivianite. Clays Clay Miner. 1999, 47 (3), 312-318.

(49) Christiansen, B. C.; Balic-Zunic, T.; Petit, P. O.; Frandsen, C.; Mørup, S.; Geckeis, H.; Katerinopoulou, A.; Stipp, S. L. S. Composition and Structure of an Iron-Bearing, Layered Double Hydroxide (LDH) - Green Rust Sodium Sulphate. Geochim. Cosmochim. Acta 2009, 73 (12), 35793592 .

(50) Halevy, I.; Alesker, M.; Schuster, E. M.; Popovitz-Biro, R.; Feldman, Y. A Key Role for Green Rust in the Precambrian Oceans and the Genesis of Iron Formations. Nat. Geosci. 2017, 10 (2), 135-139.

(51) Johnson, C. A.; Murayama, M.; Küsel, K.; Hochella, M. F. Polycrystallinity of Green Rust Minerals and Their Synthetic Analogs: Implications for Particle Formation and Reactivity in Complex Systems. Am. Mineral. 2015, 100 (10), 2091-2105.

(52) Skovbjerg, L. L.; Stipp, S. L. S.; Utsunomiya, S.; Ewing, R. C. The Mechanisms of Reduction of Hexavalent Chromium by Green Rust Sodium Sulphate: Formation of Cr-Goethite. Geochim. Cosmochim. Acta 2006, 70 (14), 3582-3592.

(53) Janney, D. E.; Cowley, J. M.; Buseck, P. R. Structure of Synthetic 2-Line Ferrihydrite by Electron Nanodiffraction. Am. Mineral. 2000, 85 (9), 1180-1187.

(54) Mullet, M.; Guillemin, Y.; Ruby, C. Oxidation and Deprotonation of Synthetic FeII-FeIII (Oxy)hydroxycarbonate Green Rust: An X-Ray Photoelectron Study. J. Solid State Chem. 2008, 181 (1), 81-89.

(55) Génin, J.-M. R.; Aïssa, R.; Géhin, A.; Abdelmoula, M.; Benali, O.; Ernstsen, V.; Ona-Nguema, G.; Upadhyay, C.; Ruby, C. Fougerite and FeII-III Hydroxycarbonate Green Rust; Ordering, Deprotonation And/or Cation Substitution; Structure of Hydrotalcite-like Compounds and Mythic Ferrosic Hydroxide. Solid State Sci. 2005, 7 (5), 545-572.

(56) Huang, L. Z.; Ayala-Luis, K. B.; Fang, L.; Dalby, K. N.; Kasama, T.; Bender Koch, C.; Hansen, H. C. 
B. Oxidation of Dodecanoate Intercalated iron(II)-iron(III) Layered Double Hydroxide to Form 2D iron(III) (Hydr)oxide Layers. Eur. J. Inorg. Chem. 2013, No. 33, 5718-5727.

(57) Ruby, C.; Abdelmoula, M.; Naille, S.; Renard, A.; Khare, V.; Ona-Nguema, G.; Morin, G.; Génin, J. M. R. Oxidation Modes and Thermodynamics of FeII-III Oxyhydroxycarbonate Green Rust: Dissolution-Precipitation versus in Situ Deprotonation. Geochim. Cosmochim. Acta 2010, 74 (3), 953-966.

(58) Cianchi, L.; Mancini, M.; Spina, G.; Tang, H. Mossbauer Spectra of Ferrihydride: Superferromagnetic Interactions and Anisotropy Local Energy. J. Phys. Condens. Matter 1992, 4 (8), 2073-2077.

(59) Massiot, D.; Dion, P.; Alcover, J. F.; Bergaya, F. 27Al and 29Si MAS NMR Study of Kaolinite Thermal Decomposition by Controlled Rate Thermal Analysis. J. Am. Ceram. Soc. 1995, 78 (11), $2940-2944$.

(60) Carlson, L.; Schwertmann, U. Natural Occurrence of Feroxyhite (d'-FeOOH). Clays Clay Miner. 1980, 28 (4), 272-280.

(61) Pollard, R. J.; Pankhurst, Q. A. Ferrimagnetism in Fine Feroxyhite Particles. J. Magn. Magn. Mater. 1991, 99 (1-3), L39-L44.

(62) Polyakov, A. Y.; Goldt, A. E.; Sorkina, T. A.; Perminova, I. V.; Pankratov, D. A.; Goodilin, E. A.; Tretyakov, Y. D. Constrained Growth of Anisotropic Magnetic $\delta$-FeOOH Nanoparticles in the Presence of Humic Substances. CrystEngComm 2012, 14 (23), 8097.

(63) Nishida, N.; Amagasa, S.; Kobayashi, Y.; Yamada, Y. Synthesis of Superparamagnetic $\delta$-FeOOH Nanoparticles by a Chemical Method. Appl. Surf. Sci. 2016, 387, 996-1001.

(64) Bo Madsen, M.; Mørup, S.; Koch, C. J. W.; Borggaard, O. K. A Study of Microcrystals of Synthetic Feroxyhite ( $\left.\delta^{\prime} \mathrm{FeOOH}\right)$. Surf. Sci. 1985, 156, 328-334.

(65) Cornell, R. M.; Schwertmann, U. The Iron Oxides; Wiley-VCH Verlag GmbH \& Co. KGaA: Weinheim, FRG, 2003; Vol. 39.

(66) Murad, E. The Characterization of Goethite by Mossbauer Spectroscopy. American Mineralogist. 1982, pp 1007-1011.

(67) Janot, C.; Gilbert, H. Caractérisation de Kaolinites Ferrifères Par Spectrométrie Mössbauer. Bull. la Société française minéralogie Cristallogr. 1973, 96, 281-291.

(68) van der Kraan, A. M.; van Loef, J. J. Superparamagnetism in Submicroscopic $\alpha$-FeOOH Particles Observed by the Mössbauer Effect. Phys. Lett. 1966, 20 (6), 614-616.

(69) Kone, T.; Hanna, K.; Abdelmoula, M.; Ruby, C.; Carteret, C. Reductive Transformation and Mineralization of an Azo Dye by Hydroxysulphate Green Rust Preceding Oxidation Using $\mathrm{H} 2 \mathrm{O} 2$ at 
Neutral pH. Chemosphere 2009, 75 (2), 212-219.

(70) Murad, E. Magnetic Properties of Microcrystalline Iron (III) Oxides and Related Materials as Reflected in Their Mössbauer Spectra. Phys. Chem. Miner. 1996, 23, 248-262.

(71) Mørup, S.; Bo Madsen, M.; Franck, J.; Villadsen, J.; Koch, C. J. W. A New Interpretation of Mössbauer Spectra of Microcrystalline goethite: "Super-Ferromagnetism” or "super-Spin-Glass" behaviour? J. Magn. Magn. Mater. 1983, 40 (1-2), 163-174.

(72) Murad, E. Magnetic Properties of Microcrystalline Iron (III) Oxides and Related Materials as Reflected in Their Mössbauer Spectra. Phys. Chem. Miner. 1996, 23 (4), 248-262.

(73) Refait, P.; Abdelmoula, M.; Génin, J.-M. R. Mechanisms of Formation and Structure of Green Rust One in Aqueous Corrosion of Iron in the Presence of Chloride Ions. Corros. Sci. 1998, 40 (9), 15471560.

(74) Refait, P.; Abdelmoula, M.; Trolard, F.; Génin, M.; Ehrhardt, J.; Bourrié, G. Mössbauer and XAS Study of a Green Rust Mineral ; the Partial Substitution of Fe 2 + by Mg 2. Am. Mineral. 2001, 86 (Taylor 1981), 731-739.

(75) Shannon, R. D. Revised Effective Ionic Radii and Systematic Studies of Interatomic Distances in Halides and Chalcogenides. Acta Crystallogr. Sect. A 1976, 32 (5), 751-767.

(76) Michel, F. M.; Ehm, L.; Antao, S. M.; Lee, P. L.; Chupas, P. J.; Liu, G.; Strongin, D. R.; Schoonen, M. A. A.; Phillips, B. L.; Parise, J. B. The Structure of Ferrihydrite, a Nanocrystalline Material. Science (80-. ). 2007, 316 (5832), 1726-1729.

(77) Wyckoof, R. W. G. Crystal Structures, Second edi.; Interscience Publishers: New York, 1963.

(78) Wander, M. C. F.; Rosso, K. M.; Schoonen, M. A. A. Structure and Charge Hopping Dynamics in Green Rust. J. Phys. Chem. C 2007, 111 (30), 11414-11423.

(79) Wei, Y.; Ding, R.; Zhang, C.; Lv, B.; Wang, Y.; Chen, C.; Wang, X.; Xu, J.; Yang, Y.; Li, Y. Facile Synthesis of Self-Assembled Ultrathin $\alpha-\mathrm{FeOOH}$ Nanorod/graphene Oxide Composites for Supercapacitors. J. Colloid Interface Sci. 2017, 504, 593-602.

(80) Cheng, W.; He, J.; Yao, T.; Sun, Z.; Jiang, Y.; Liu, Q.; Jiang, S.; Hu, F.; Xie, Z.; He, B.; Yan, W.;

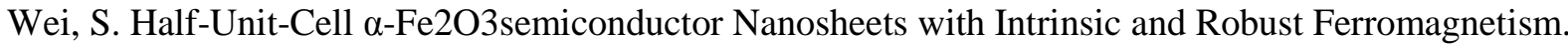
J. Am. Chem. Soc. 2014, 136 (29), 10393-10398.

(81) Shao, P.; Ren, Z.; Tian, J.; Gao, S.; Luo, X.; Shi, W.; Yan, B.; Li, J.; Cui, F. Silica HydrogelMediated Dissolution-Recrystallization Strategy for Synthesis of Ultrathin A-Fe2O3nanosheets with Highly Exposed ( $\left.1 \begin{array}{ll}1 & 1\end{array}\right)$ ) Facets: A Superior Photocatalyst for Degradation of Bisphenol S. Chem. Eng. J. 2017, 323, 64-73.

(82) Yang, Y.; Zhong, Y.; Wang, X.; Ma, Y.; Yao, J. Facile Synthesis of Ultrathin Lepidocrocite 
Nanosheets from Layered Precursors. Chem. - An Asian J. 2014, 9 (6), 1563-1569.

(83) Chen, P.; Xu, K.; Li, X.; Guo, Y.; Zhou, D.; Zhao, J.; Wu, X.; Wu, C.; Xie, Y. Ultrathin Nanosheets of Feroxyhyte: A New Two-Dimensional Material with Robust Ferromagnetic Behavior. Chem. Sci. 2014, 5 (6), 2251-2255.

(84) Sestu, M.; Carta, D.; Casula, M. F.; Corrias, A.; Navarra, G. Novel Interpretation of the Mean Structure of Feroxyhyte. J. Solid State Chem. 2015, 225, 256-260.

(85) Drits, V. A.; Sakharov, B. A.; Manceau, A. Structure of Feroxyhite as Determined by Simulation of X-Ray Diffraction Curves. Clay Miner. 1993, 28 (2), 209-222.

(86) Lee, S.; Shen, Z.; Xu, H. Study on Nanophase Iron Oxyhydroxides in Freshwater Ferromanganese Nodules from Green Bay, Lake Michigan, with Implications for the Adsorption of As and Heavy Metals. Am. Mineral. 2016, 101 (9), 1986-1995. 